\title{
SEISMIC RESPONSE OF LOW-RISE BUILDINGS
}

\author{
P. J. Moss' ${ }^{1}$ A. J. Carr ${ }^{1}$ and A. H. Buchanan²
}

\section{ABSTRACT}

The results of an investigation into the dynamic response of several lowrise structures are reported. The main parameters studied were the effect of variations in the form of the hysteresis loop exhibited by the inelastic members and of differing types of earthquake accelerograms.

\section{$1.0 \quad$ INTRODUCTION}

The section of the New zealand Loadings Code NZS 4203 [7] dealing with the seismic analysis of structures gives a number of multiplicative factors that are to be used for determining the lateral seismic design force. Two of these factors are ' $S$ ' - the structural type factor, and ' $M$ ' - the material factor. The $S$ and $M$ values appropriate for reinforced concrete and for steel framed buildings have largely been derived on the basis of the past performance of multistorey buildings in these materials. In the case of timber structures a single combined 'SM' factor has been included in the code with the values for the different types of timber structure being chosen on the basis of the performance of those particular structural forms. However, with the recent and continuing development of new forms of steel and timber structures it has become necessary to reassess the values currrently being used for low-rise buildings in timber and other materials.

\subsection{BACKGROUND}

\subsection{Equal-Displacement Concept}

The basic assumption behind the seismic provisions of NZS 4203 is the "equal-displacement" concept.

Stated simply, this theory requires that if a structure is designed to yield at a force which is some fraction, $1 / R$, of the elastic response force, then the structure must be capable of accommodating a displacement of $\mu$ times the yield displacement, the ductility $\mu$ being equal to $\mathrm{R}$.

The design seismic base shear prescribed in NZS 4203 is based on one quarter of elastic response. Hence designs using $S M=1.0$ are required to have a ductility capability of $\mu=4.0$. If the equal displacement theory is assumed to hold. less ductile structures can be designed for larger shear forces, increased

1 Department of Civil Engineering,

2 University of Canterbury

2 Buchanan and Fletcher Ltd, Christchurch by the SM factor, in which cases the required ductility drops linearly according to

$$
\mu=s^{\frac{4}{M}}
$$

It has been generally assumed in the past that this basic concept only applies to structures which have elasto-plastic or similar hysteretic behaviour.

\subsection{Timber Erames}

Seismic design of timber structures requires an understanding of the engineering properties of timber and the resulting behaviour of various structural systems. Figure I shows typical stressstrain relationships for timber in tension and compression, both parallel to and perpendicular to the grain. Tension failures in either direction are brittle as are shear failures and most bending Failures. Compression loading produces ductile behaviour. Bending behaviour depends on the ratio of tension to compression strength. If wood is stronger in tension than in compression, bending strength is governed by compression strength and bending failures tend to be

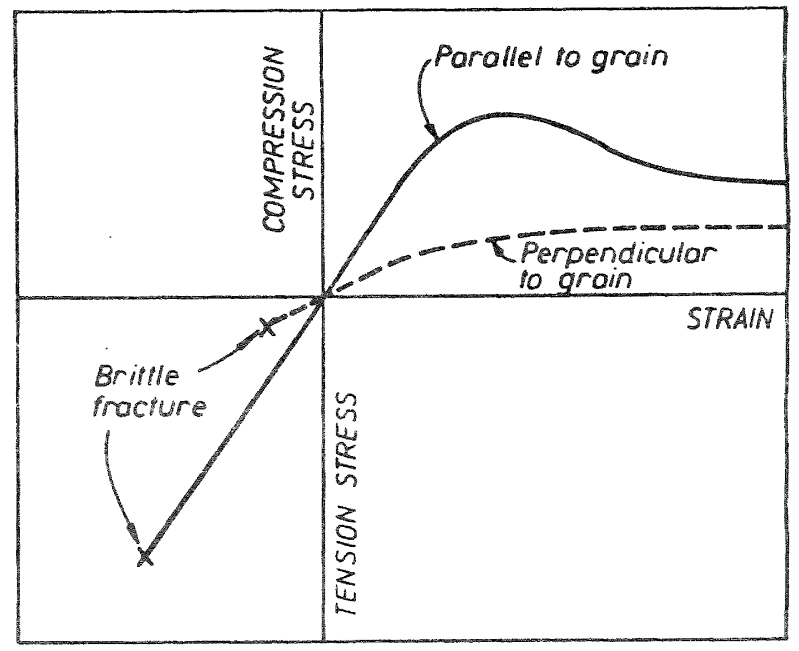

Fig. 1 Stress-Strain Relationships for Wood 
ductile, not brittle.

This is generally the case for small clear specimens. especially if the wood is green. In most full size members (sawn timber or laminated timber in commercial grades), the material is weaker in tension than in compression with the result that bending failures are sudden brittle fractures. This is particularly true for the weaker members of any population.

While the strength of timber is known to be very variable, there is not yet any method available to predict the strength of individual pieces. Nevertheless, this variability must be considered for several reasons. The design stress for a single piece is based on the lower fifth percentile strength value for the population. If several members share a load, design stresses can be increased to allow for the reduced variability resulting from load-sharing. In a structure with no redundancies, some individual members may be weaker than the fifth percentile design value. Thus the variability in timber strength makes it difficult to carry out a "capacity design" procedure since it can be difficult to ensure that a particular timber member is stronger than an associated ductile connection.

Moment resisting timber frames are becoming increasingly popular yet many current design practices are suspect because the available ductility may be much lower than assumed by designers. On the other hand, many of these structures are relatively flexible and with longer than expected natural period would be subject to a lower seismic force than that normally designed for.

The three main connection systems for timber frames are glued joints, steel gussett plates and plywood gussett plates.

Glued connections: Structures with rigid connections will suffer brittle failure in the glue or in the timber if loaded to failure. The loaddeflection plot will generally be linear or slightly nonlinear. Such structures should be designed as elastically responding structures.

(b) Nailed gussett connections: Nailed gussett connections in moment resisting timber frames can behave in a ductile manner if the nails themselves are the weakest link in the system. If the connections can be detailed so that 'plastic hinges' can occur then the frames can be designed as ductile even if the hysteresis loops show pinching behaviour. If overload would produce a brittle failure in the timber then the frame should be designed to respond elastically.

The timber design code, NZS 3603 , makes it difficult to achieve a ductile connection because it greatly underestimates the strength of nails loaded in shear. Nails through plywood have a strength 2 or 3 times the permissible seismic loading values but timber (at the fifth percentile level) has a capacity only about 1.5 times the permissable code values. An apparently simple design can therefore lead to the intended ductile connection being stronger than the potentially brittle members being connected. This discrepancy is even larger if steel gussett plates are used because NZS 3603 has lower seismic design values for nails through steel than through plywood whereas in practice the opposite is true.

Clause 2.12 of NZS 3603 has a provision requiring this problem to be considered and prevented unless an elastic design is carried out. The result of such an exercise, following the code, can produce members which are considerably over-designed. The most realistic solutions are:

(1) to use more realistic nail strength values than provided in the code (though this may give a very flexible connection) or

(2) to design all moment resisting timber frames for elastic response, or

(3) ensure a plastic hinge where required by incorporating a yielding structural steel element in which case it can be designed as a ductile steel member.

\subsection{Timber Shear Walls}

Timber shear walls incorporating plywood or other wood based sheathing materials are widely used for lateral load resistance in timber structures. These structures have not been investigated in this study because they are the subject of a continuing comprehensive study which is making similar findings (Dean, stewart and Carr $[10]$ ).

\subsection{Steel Frames}

Ductile steel frames have performed well under seismic attack. Compared with timber, steel has much more ductile material properties and welded connections are relatively simple. Innovations in steel structures include $\mathrm{K}$-braced frames whose seismic performance is not well understood.

\subsection{STRUCTURE MODEL}

The aim of the study was to structures having limited ductility when subjected to a series of earthquake accelerograms in an attempt to obtain estimates of the appropriate ' $S M$ ' to be used in the design of such structures. Part of the study was to gauge the effect of variation in the forms of the hysteresis loop exhibited by the inelastic members and to see how the response varied with differing types of earthquake accelerograms.

For the first part of this investigation a portal frame structure was chosen. This frame has a span of 10 metres 
and a height of 3 metres. The columns are assumed to be pinned at their bases. The portal is considered to be typical for that of a factory building having tilt-up concrete walls which introduce a large mass at roof level. This is to ensure that seismic forces are more significant than wind forces in the design of the portal.

This investigation has considered portals of two materials. The "timber" structure has glued laminated timber members, of rectangular cross-section with nailed moment-resisting knee joints incorporating steel side plates. The weakest link in this structure is intended to be in the nails at the top of the columns. The model assumes that these nails yield at the design level of loading (although it is recognised that it is difficult to define the yield point for a nailed connection which tends to exhibit nonlinear behaviour from quite low levels of load). The nails themselves have not been modelled but the members have been given moment-curvature characteristics intended to represent yielding in the nailed joint.

The "steel" structure consists of structural steel Universal Beam sections welded together with rigid knee joints. The model is based on yielding occurring at the top of each column at the design level of loading.

In both models, rigid end-blocks of suitable proportions were provided to represent the stiff joint region at the knee joint where the beam and column intersect.

The later parts of the investigation have considered, to a lesser extent, variations of the simple portal frame in the form of a cross-braced portal frame, a $\mathrm{K}$-braced two storey steel frame, and a four storey timber frame.

\subsection{Portal Design}

Initially the portal was designed to NZS 4203. However, the critical member sizes were such that the structure had a very long period $(4.2$ seconds for a steel portal and 2.1 seconds for the timber portal) which did then not agree with the period used in deducing the initial design forces. Stiffening the members in order to reduce the period resulted in the frames remaining elastic when analysed under the El Centro May 1940 accelerogram, instead of exhibiting the ductility implied in the code design.

As a result, the following design strategy was evolved so that a portal having a specified period of free vibration could be subjected to both code seismic forces and those from any particular earthquake spectrum. This enables a comparison to be achieved between the ductility implied in the design and that exhibited during the dynamic analysis.
(1) Decide on the required natural period assuming a particular mass and geometry.

(2) Determine the spectral force associated with elastic response from the acceleration spectrum of the chosen earthquake accelerogram for five percent damping.

(3) Reduce the elastic spectral force by the reduction factor $R$ to obtain the required inelastic force. (This implies the equal-displacement principle holds in relating the forces of the elastic and inelastic structures.)

(4) Design the columns to just reach yield at the inelastic force from Step 3 above.

(5) Select a girder of stiffness such that the portal will have the required natural period selected in Step 1 above.

Since the natural period $T=2 \pi \sqrt{\mathrm{FM}}$

where $M=$ total mass

$E$ = frame flexibility

$=\frac{1}{6 E}\left[\frac{H^{2}\left(L-2 L_{e}\right)^{3}}{2 I_{G} L^{2}}+\frac{\left(H-H_{e}\right)^{3}}{I C}\right]$

with

E $\quad=$ Elastic modulus

$\mathrm{H}, \mathrm{L}=$ Height and span, respectively

$\mathrm{H}_{e}, \mathrm{I}_{e}=$ End-block lengths at each column and girder respectively

$I_{C}: I_{G}=$ second moments of area of column and girder respectively.

This assumes no axial deformation in columns.

(6) Subject the modelled portal to the chosen earthquake accelerogram used in step 2 .

(7) From the analysis output, determine the maximum ductility $\mu$ required from the frame during the earthquake. This leads to the factor $\mu / R$.

The portal frames designed to resist the spectral force from the El Centro 1940 earthquake were used for all the analyses rather than redesigning the frames for each accelerogram used. Nevertheless. the individual earthquake spectra were used to calculate the force reduction factor. $R$, relating the elastic spectral force to the design inelastic force.

\subsection{Structures Analysed}

(a) Timber and steel portal frames

Portal frames were designed to have periods of $0.5,1.0,1.5$ and 2.0 seconds with the column and girder sizes being shown in Table 1 . 


\begin{tabular}{|c|c|c|c|c|c|c|c|}
\hline \multirow{2}{*}{\multicolumn{2}{|c|}{$\begin{array}{l}\text { Approx. } \\
\text { Period } \\
\text { (secs) }\end{array}$}} & \multicolumn{3}{|c|}{ Tinber } & \multicolumn{3}{|c|}{ Steel } \\
\hline & & $R=1$ & $R=2$ & $R=4$ & $R=1$ & $R=2$ & $R=4$ \\
\hline 0.5 & $\begin{array}{l}\text { Column } \\
\text { Girder }\end{array}$ & $\begin{array}{l}883 \times 140 \\
730 \times 140 \\
720 \times 140\end{array}$ & $\begin{array}{r}623 \times 140 \\
1000 \times 140\end{array}$ & $\begin{array}{r}442 \times 140 \\
1700 \times 140\end{array}$ & $\begin{array}{l}460 \text { UB } 67 \\
460 \text { UB } 75\end{array}$ & $\begin{array}{l}310 \text { UB } 40 \\
760 \text { UB } 244\end{array}$ & $\begin{array}{l}305 \text { I } 102 \times 28 \\
914 \text { I } 419 \times 387\end{array}$ \\
\hline 1.0 & $\begin{array}{l}\text { Column } \\
\text { Girder }\end{array}$ & $\begin{array}{l}648 \times 140 \\
460 \times 140\end{array}$ & $\begin{array}{l}458 \times 140 \\
620 \times 140\end{array}$ & $\begin{array}{r}324 \times 140 \\
1100 \times 140\end{array}$ & $\begin{array}{c}360 \text { UB } 45 \\
305 \text { I } 102 \times 33\end{array}$ & $\begin{array}{c}250 \text { UB } \begin{array}{l}3 \\
41\end{array} \\
305 \text { I } 165 \times 52\end{array}$ & $\begin{array}{l}254 \text { I } 102 \times 18 \\
610 \text { I } 229 \times 140\end{array}$ \\
\hline 1.5 & $\begin{array}{l}\text { Column } \\
\text { Girder }\end{array}$ & $\begin{array}{l}458 \times 140 \\
365 \times 140\end{array}$ & $\begin{array}{l}324 \times 140 \\
565 \times 140\end{array}$ & $\begin{array}{r}229 \times 140 \\
1400 \times 140\end{array}$ & $\begin{array}{c}250 \text { UB } 31 \\
203 \text { I } 133 \times 31\end{array}$ & $\begin{array}{l}254 \text { I } 102 \times 18 \\
250 \text { UB } 31\end{array}$ & $\begin{array}{l}152 \text { I } 102 \times 18 \\
760 \text { UB } 148\end{array}$ \\
\hline 2.0 & $\begin{array}{l}\text { Column } \\
\text { Girder }\end{array}$ & $\begin{array}{l}416 \times 140 \\
297 \times 140\end{array}$ & $\begin{array}{l}294 \times 140 \\
375 \times 140\end{array}$ & $\begin{array}{r}208 \times 140 \\
1000 \times 140\end{array}$ & $\begin{array}{c}200 \text { UB } 30 \\
200 \text { I } 100 \times 18\end{array}$ & $\begin{array}{c}175 \text { I } 90 \times 18 \\
200 \text { UB } 30\end{array}$ & $\begin{array}{c}150 \text { I } 75 \times 14 \\
410 \text { UB } 54\end{array}$ \\
\hline
\end{tabular}

Table 1 Column and Girder Sizes Used for the Timber and Steel portal Frames

Many of the portals could not be considered to be "practical" frames in the normal sense as deflections under the code lateral load were in some cases well outside the normal design deflection limits and the girders were not designed to carry any vertical load. The member sizes were chosen solely on the basis of providing a range of periods and being able to resist the spectral lateral force associated with those periods.

\section{(b) Cross braced frames}

An end frame of the building was considered for timber frames with the columns and girders pin-connected so that all the lateral stiffness was provided by small diameter round steel rod or steel flat rod used as diagonal bracing. The cross-sectional area required for the bracing was determined from the inelastic spectral force. Since it is not possible to control both strength and stiffness when there is only one independent variable. i.e. the cross-sectional area of the bracing, this gave a Erame having a period of 0.36 seconds when $R=2$ and 0.47 seconds when $R=4$.

For the inelastic analyses, the braces were modelled as elastoplastic with a compressive yield strength of zero. Slackness in the bracing system was allowed to develop as the braces yielded in tension and as well the braces could be given a predetermined "lack-of-fit" which had to be taken up before the braces could resist tension forces.

\section{K-braced two storey steel Erame}

Rather than design a range of $\mathrm{K}$ braced frames of particular periods, one of the frames in the HERA building in Auckland was chosen for study - see Figure 2a. On account of the shape of the building, the particular frame was required to resist part of a large torsional force on the building in additional to the direct lateral forces. Also, the size of the bracing used between the ground and the firgt floor beam had been chosen in order

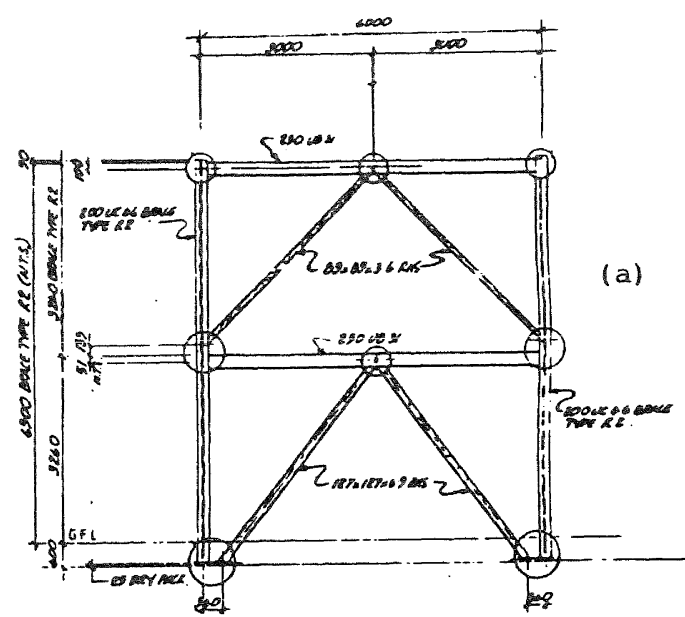

ELEVATION BRACE TYPE R2.

scals 1:s

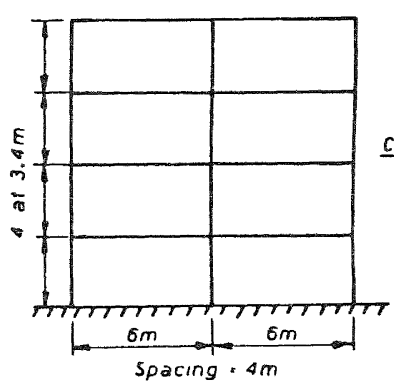

- Member Stzes-

Beams: Roof $\div 250 \times 300 \mathrm{~mm}$ Floor $5 \div 250 \times 400 \mathrm{~mm}$ Columns: Exterior $+250 \times 300 \mathrm{~mm}$ Interior $\div 250 \times 400 \mathrm{~mm}$

(b)

Fig. 2 Dimensions for

(a) two storey $k$-braced steel frame, and

(b) four storey timber frame

to keep the slenderness ratio to a maximum of 80 while this was relaxed to 135 for the Eirst floor bracing since it was designed to remain elastic. The design lateral loads were $44 \mathrm{kN}$ at roof level and $280 \mathrm{kN}$ at first floor level. 
Initial analyses of the frame showed that the response under the El Centro 1940 earthquake was fully elastic and the natural period was very short. Eor the final analyses, in order to lengthen the period and provide yielding in the ground floor bracing, the storey weights were taken as $50 \mathrm{kN}$ at roof level and $640 \mathrm{kN}$ at first floor level giving a natural period for the frame of 0.25 seconds.

\section{Four storey moment-resisting timber frame}

An interior frame, taken as being loaded in its own plane, was designed in accordance to NZS 3603 [8] to resist the loads set out in NZS 4203 [7]. An outline of the frame is shown in figure $2 b$, together with the sizes of the glulam members used for the beams end columns. The columns were assumed to be fabricated in one length with the beams being connected to the columns by means of nailed gussett connections with steel side plates. these nailed connections having a yield strength of $40 \mathrm{kNm}$. The natural period for the frame was 0.94 seconds.

\subsection{ANALYSIS PROGRAM}

The computer program used for the analyses is a dynamic time-history analysis program designed to produce a piece-wise time-history response of a nonlinear general two-dimensional framed structure to ground aceleration excitation. The damping model used may be Rayleigh damping based on the tangent stiffness or the initial stiffness. Alternatively the damping model may give a linear or trilinear variation with frequency. Beam members are represented by an elastic menber of stiffness EI with rotational springs at each end to provide the elastic/post-elastic behaviour. the stiffness of the springs being varied according to the particular post-elastic stiffness model being followed.

\subsection{Hysteresis Loops}

The range of hysteresis rules considered for the behaviour of the plastic hinges forming at the top of the columns are as follows:

(a) Elasto-plastic (EP) this is the rule generally assumed in the "equaldisplacement" concept which is applied in the design of structures subjectec to seismic attack.

(b) Bi-linear (B) similar to the Elastoplastic loop but exhibiting some strain-hardening beyond the yield point. As the Moment-Curvature properties of most timber connections do not have a sharply defined yieldpoint the elasto-plastic rules are not totally appropriate for these structures. By varying the yield moment and the bi-linear factor, a better idealisation of the curved moment-curvature relationship may be obtained. (c) Ramberg-Osgood (RO) rules were initially used to represent the inelastic behaviour of steel sections as they gave a reasonable modification of a bi-linear hysteresis in allowing for the gradual transition from elastic to inelastic and the modelling of the Bauschinger effect. The rule has become less popular in recent years because, with its continually changing stiffness, it is computationally expensive, and, as discussed below, the actual detail of the hysteresis loop does not appear to be particularly important in the resulting dynamic response.

(d) Degrading Stiffness $(C, Q, T)$ rules were intended to represent the degradation in the stiffness of reinforced concrete subjected to cyclically repeated inelastic excursions. The early rules proposed by Clough have been followed by many others, such as Q-HYST and Takeda, which have attempted to get more and more realistic, and more and more complex representations of the inelastic behaviour of the members

(e) pinched (K) hysteresis loops were developed by kivell [1] for nailed timber joints. These show the pinching loop often found in such joints. The initial back-bone or "spine" curve is still a bi-linear moment-curvature relationship. If a negative bi-linear factor is used the 'Kivel1' hysteresis rule represents a pinched system with a degrading strength as well as stiffness.

These rules are illustrated in Eigures 3 and 4 .

\subsection{Degrading Strength}

These rules were intended to represent the degradation in strength that occurs in a number of materials subjected to cycilcally repeated inelastic excursions. For this study, the initial back-bone or "spine" curve was an elastoplastic monent-curvature relationship in order to give behaviour that could be compared with the results given by rule (a). Three forms of strength degrading were considered, viz (i) the reduction being a function of the ductility in each direction, (ii) the reduction being a function of the number of cycles of inelastic behaviour, and (iii) the reduction being a function of the maximum ductility reached in either direction. This is illustrated in Eigure 5 .

\subsection{Earthquake Accelerograms}

(a) The El Centro May 1940 North-South component was the accelerogram used for the major part of this analysis. Athough this record is no longer regarded as representing a strong earthruake and is also now regarded as being not very typical of an earthquake excitation, it is representative of the acceleration levels found in many of the world seismic codes. This is due to the fact that up until about 1965 , i.e. 


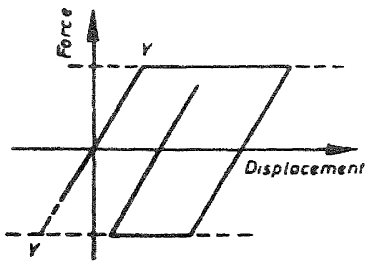

(a) ELASTO-PLASIIC MOOEL

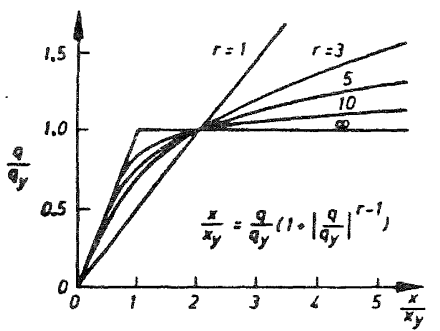

(c) RAMBERG-OSGOOD FUNCTIONS

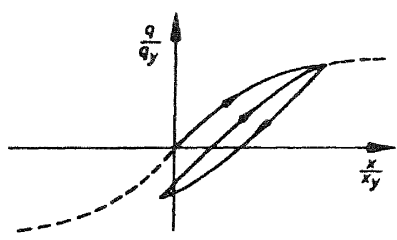

IdL RAMBERG.OSGOOO LOAD.DISPLACEMENT RELATIONSHIPS

Fig. 3 Elasto-Plastic, Bilinear and RambergOsgood Hysteresis Models

the time by when most seismic design codes had come into being, it represented the largest recorded ground acceleration and ground velocity. It was orecords such as this that most of the early work leading to the concept of the "equaldisplacement" concept was developed.

(b) An example of another record from the same area is the El Centro 1979 earthquake recorded at the free-field site near the Imperial county Services Building in El centro. The peak acceleration is not quite as high as that for the 1940 record.

(c) The 1966 Parkfield record was taken as being an example of an accelerogram recorded near the epicentre of the earthquake. A major feature of the accelerogram is the large triple peak followed by a rapidly decaying tail.

(d) Two artificial earthquakes were generated by the program SIMQKE [2] to have response spectra to match as closely as possible, the spectrum of NZS 4203 (multiplied by 4.0 to obtain the elastic spectrum) and to match the spectrum produced by the New Zealand Earthquake Engineering Bridge Design study Group [3].

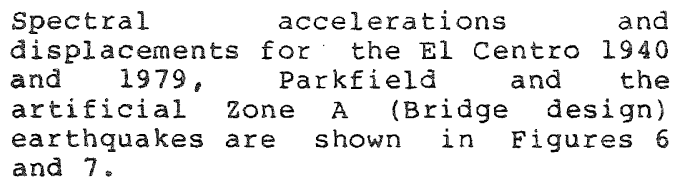

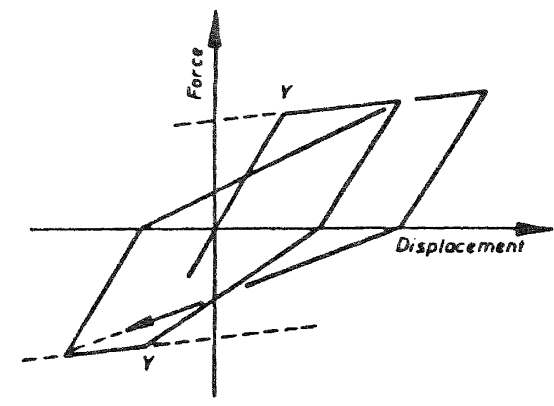

(a) CLOUGHS OEGRAOING STIFFNESS MOOEL

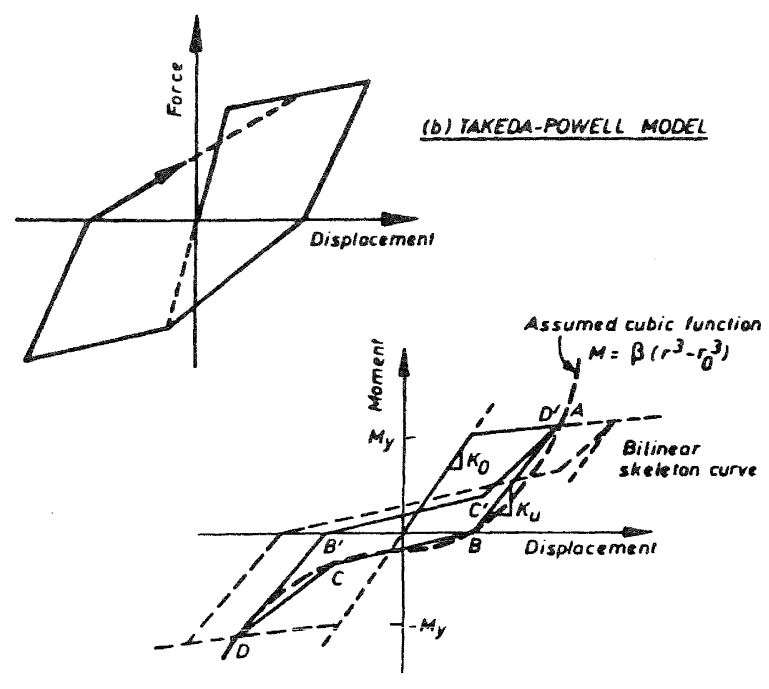

(c) KIVELL'S PINCHING MODEL

Fig. 4 Clough, Takeda-Powell and Kivell Hysteresis Models

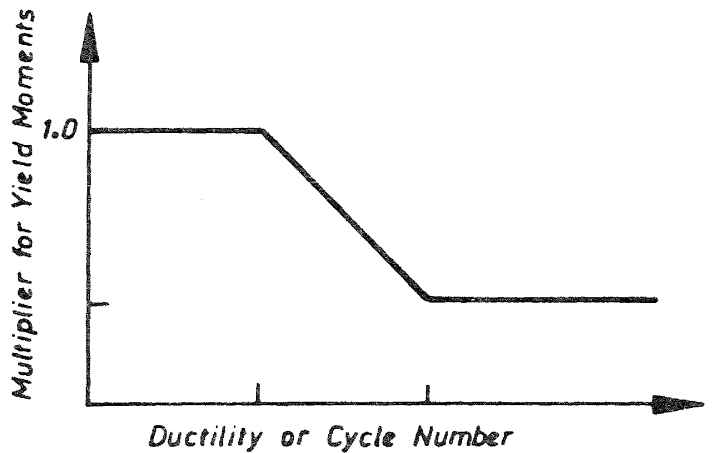

DEGRADING STRENGTH MODEL

Fig. 5 Degrading Strength Hysteresis Model 


\subsection{RESULTS}

\section{(a) Timber Portals}

The required ductility factors, $\mu$, are shown plotted against the period in Figure 8 for the elastoplastic, bilinear and pinching hysteresis models under the El Centro 1940 earthquake. The figure shows considerable variation from one hysteresis model to another as well as considerable variation with period for each model. While the case where $R=1$ implies elastic behaviour, the frames nevertheless have a yield moment above the design value and hence the sections can yield in an earthquake if the actual seismic forces exceed the values implied by the smooth spectra used in the design code. As would be expected though, the variation for $R=1$ is slight compared with that for $R=2$ and $R=4$ over the range of natural periods studied.

Figure 9 shows the ratio $\mu / R$ plotted against period for the different hysteresis rules under the El Centro 1940 earthquake. If the design forces were accurate then the trend for all values of $R$ should be constant at 1.0 .

Similar results for the elastoplastic frames subjected to the Parkfield earthquake are shown in Figure 11. Since the frames had been designed for the EI Centro 1940 earthquake spectra, the ductilities required under the Parkfield earthquake are greater and the $\mu / R$ ratios are more varied as well.

The influence of earthquake and hyste resis model are shown in differing ways in Eigures 12, 14 - 16. In order to examine the effect of different earthquake spectra, the $\mu / R$ ratio is shown plotted in Figure 12 for elastoplastic frames having $R=4$. The results for the El Centro 1940 earthquake are nearly constant at 1.0 as should be expected. since it formed the basis for the code requirements, but varies very considerably for the other earthquakes and is usually much greater than 1.0. The influence of hysteresis model and earthquake is shown in Figure 14 where it can be seen that the different hysteresis models give merely a perturbation on the effect of the different earthquakes. The elastic response and the inelastic responses of the frames are shown in Figure 15 and 16 where the knee moment is plotted against horizontal displacement at the knee. (The letters refer to the different hysteresis models and any numbers to a variation in one of the parameters in the model.) The $\mathbf{R}=1$ (elastic), $\mathbf{R}=2$ and $R=4$ (inelastic) responses are shown with a view to determining whether or not the "equal-displacement" concept holds for inelastic structures.

In order to see whether or not the "equal-displacement" concept holds for short period structures, three additional frames were designed for $\mathrm{R}=4$ and periods of $0.2,0.3$ and 0.4 seconds. The results for the elastic and inelastic (elastoplastic and pinching) responses are shown in Figure 17.

\section{(b) Steel Portals}

The required ductility factors under the El Centro 1940 earthquake are shown in Figures 8 and 10 for elastoplastic and Ramberg-Osgood hysteresis models, with the resulting $\mu / R$ ratios being shown in Figures 9 and 10. Similar results for the Parkfield earthquake are shown in Figure 11. Considerable variation can be seen in the results, in some cases even for the frames designed for $R=1$.

The influence of different earthquake records on the response can be seen in the variations shown in Figure 13 for the $\mu / R$ ratio.

In order to study the effect of strength degradation on the inelastic response, a number of analyses were carried out where the strength reduced over either a range of cycles or over a range of ductility (see Eigure 5). The results of these analyses are compared with the elastic and several other inelastic responses in Figure 20 . The symbol ' 2 ' refers to a strength degradation over 4 cycles with a residual strength of $80 \%$. The other numeric symbols refer to analyses where the strength degraded over the range from a ductility of 1.0 to 5.0 with residual strengths of $80 \%$ and $60 \%$ for ' 1 ' and ' 3 ' respectively and 408 for ' 4 ' and ' 5 '. Case ' 5 ' differed from case ' 4 ' ' in that the reduction was based on the maximum ductility whether positive or negative while all the other cases treated the positive and negative direction ductilities as separate. Figure 20 shows the range of scatter for the results as well as showing the considerable variation that occurs over the period range studied.

\section{(c) Cross-Braced Erames}

Plots of maximum axial force in one of the bracing members against maximum horizontal knee deflection are shown in figure 21. The difficulty of matching strength, stiffness and natural period was such that the three frames with different $\mathbb{R}$ values responded with different periods. thus making it difficult to compare the results for the three frames.

The frame designed for $R=1$ had an actual $R$ of 0.725 , a period of 0.217 seconds and no yielding took place (a required ductility of 0.78 ). The $R=2$ frame had an actual $R$ of 1.90 , a period of 0.365 seconds and a required ductility of 2.83, while the $R=4$ frame had an actual $R$ value of 3.72 a period of 0.470 seconds and a required ductility of 4.31 .

For the cases where the slackness in the bracing is $25 \mathrm{~mm}$ and $50 \mathrm{~mm}$, the required ductilities are 0.92 and 0.63 for the $R=1$ case, 2.33 and 1.13 for the $R=2$ case and 3.20 and 2.52 for the $R=4$ case. The greater elastic response in the case of the $R=4$ frame is explained by the greater spectral acceleration (and hence force) at the period of this frame than for the other two frames (see fig. 6). 


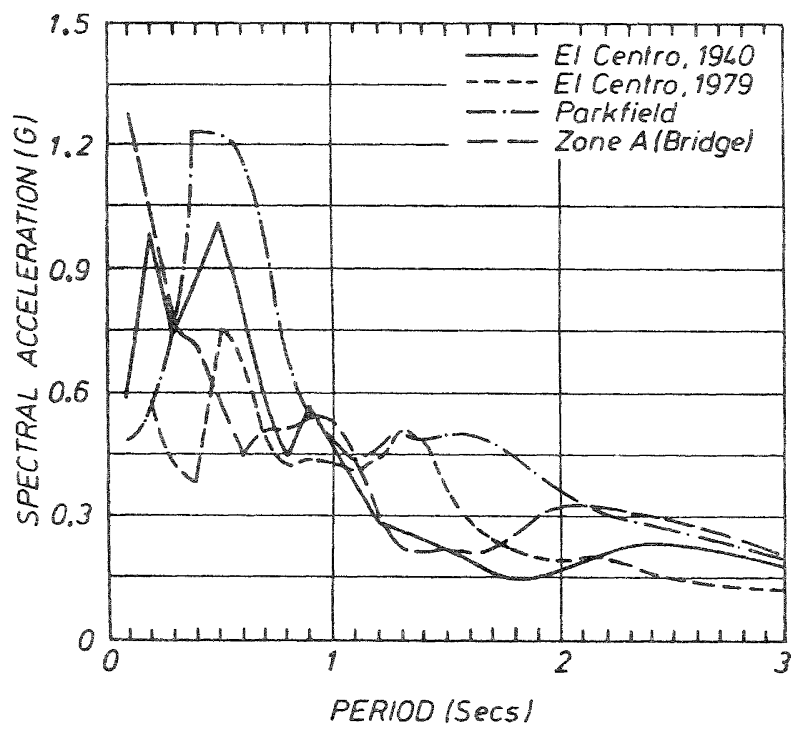

Fig. 6 Spectral Accelerations for the El Centro 1940 and 1979, Parkfield and Artificial Zone A (Bridge) Earthquakes

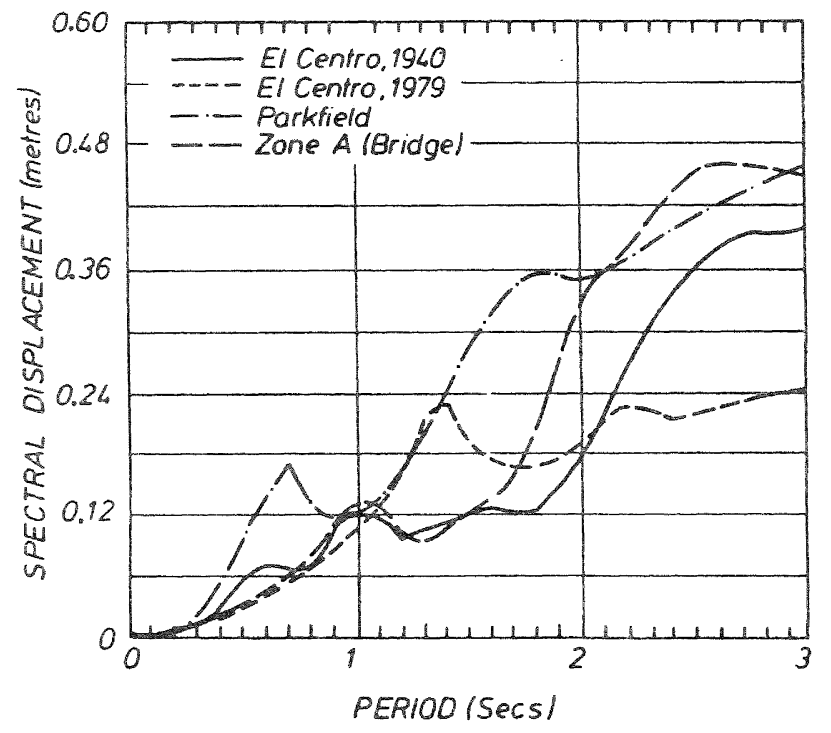

Fig. 7 Spectral Displacements for the El Cemtro 1940 and 1979, Parkfield and Artificial Zone A (Bridge) Earthquakes
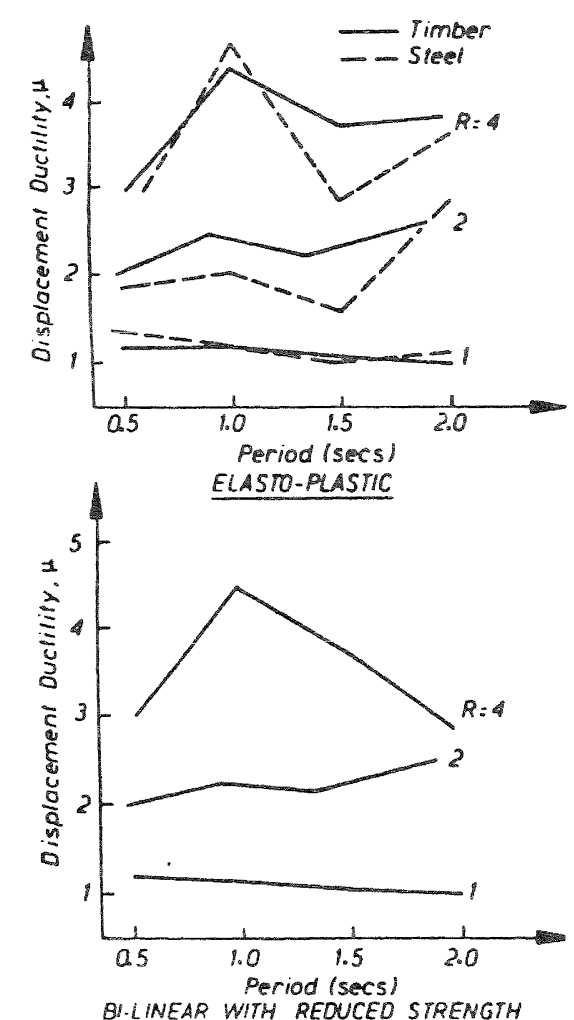

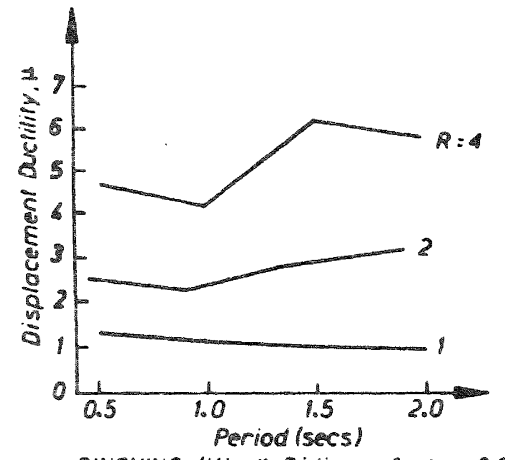

PINCHING (Kivell. Bitinear focior: 0.01

Fig. 8 Ductility Factors for Portal Frames Subjected to El Centro May 1940 and Having Different Hysteresis Rules 

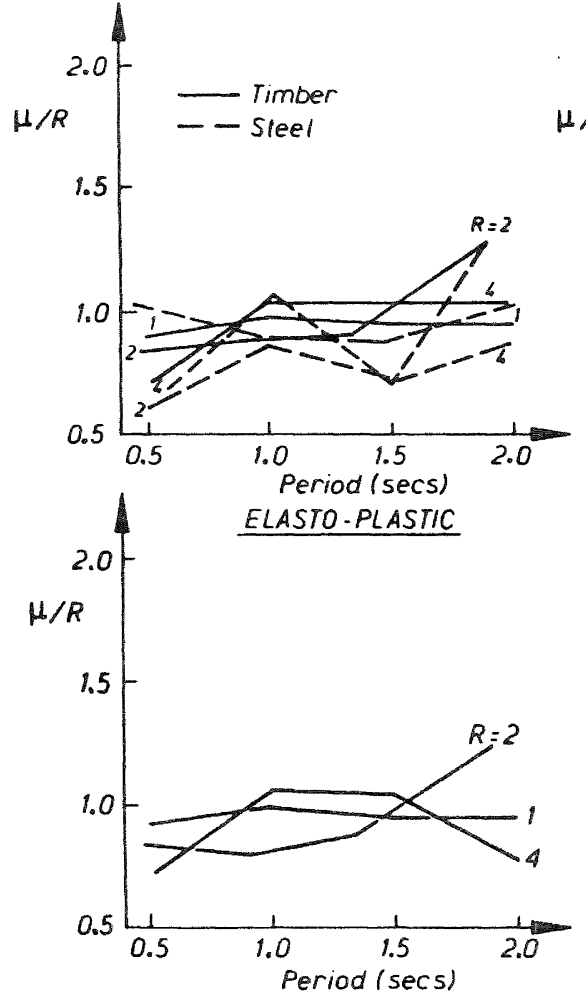

BI-LINEAR WITH REDUCED STRENGTH

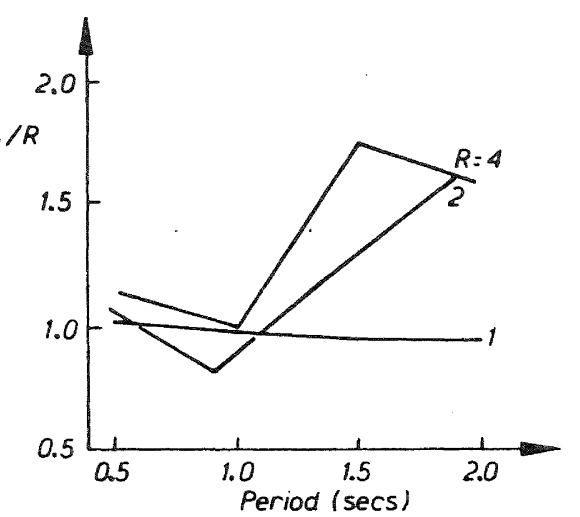

PINCHING (Kivell. Bi-linear faclor $=0.0$ )

Fig. $9 \mu / R$ Factors for Portal Frames Subjected to El Centro May 1940 and Having Different Hysteresis Rules
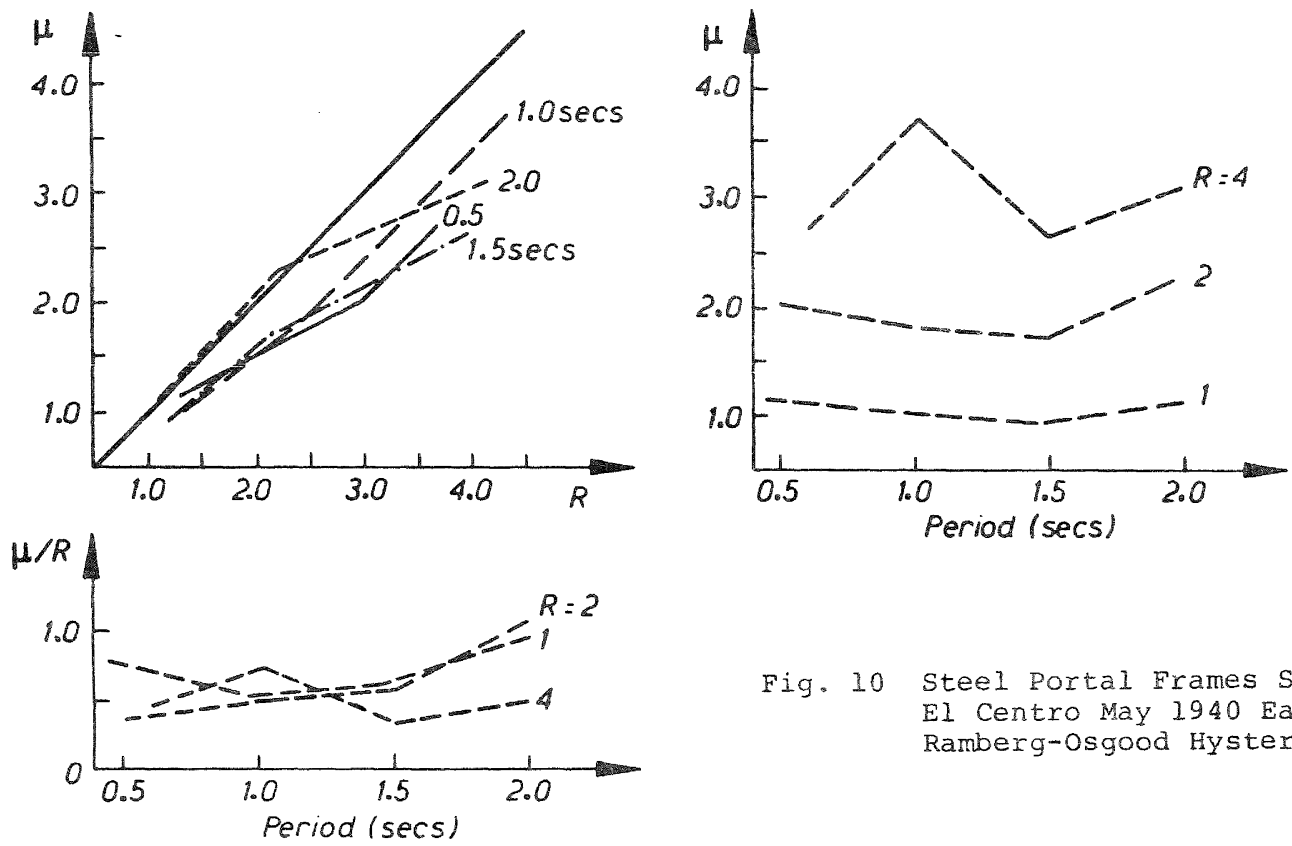

Fig. 10 Steel Portal Frames Subjected to El Centro May 1940 Earthquake Ramberg-Osgood Hysteresis $(r=7)$ 

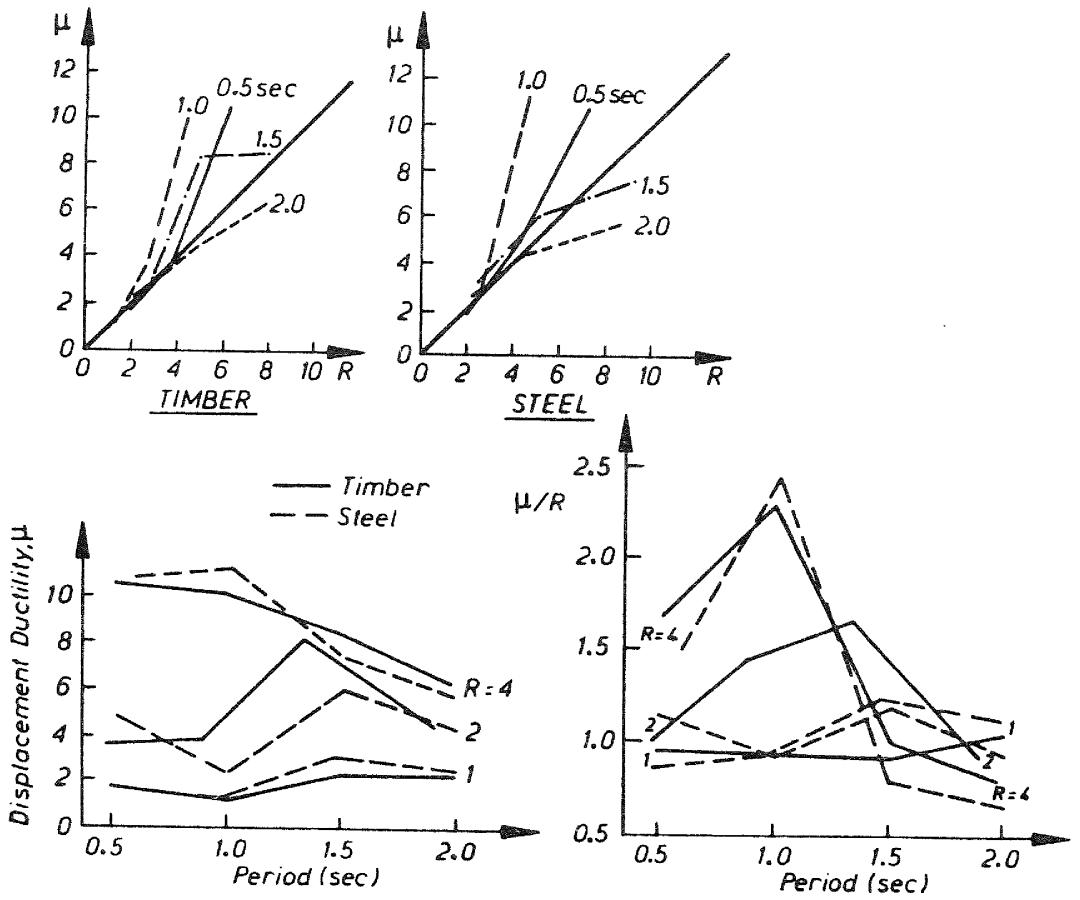
Fig. 11 Elasto-Plastic Portal Frames Subjected to the
Parkfield Earthquake

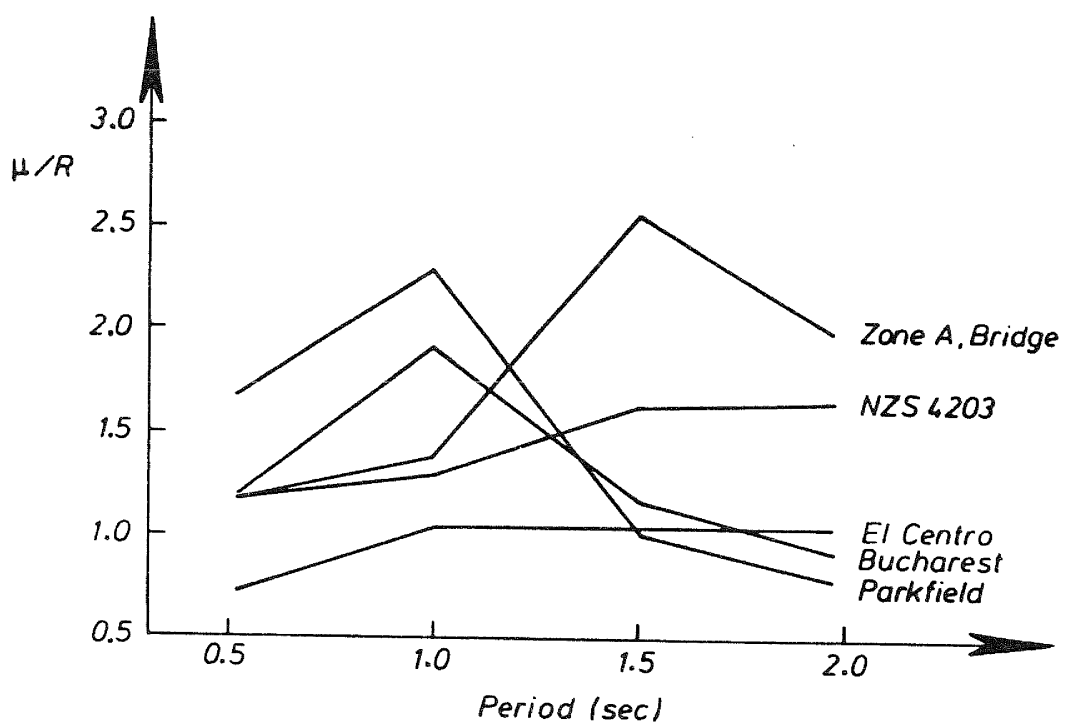

Fig. $12 \mu / R$ Factor for Elasto-Plastic Timber Frames Designed with $R=4$ Subjected to Various Earthquake Excitations 


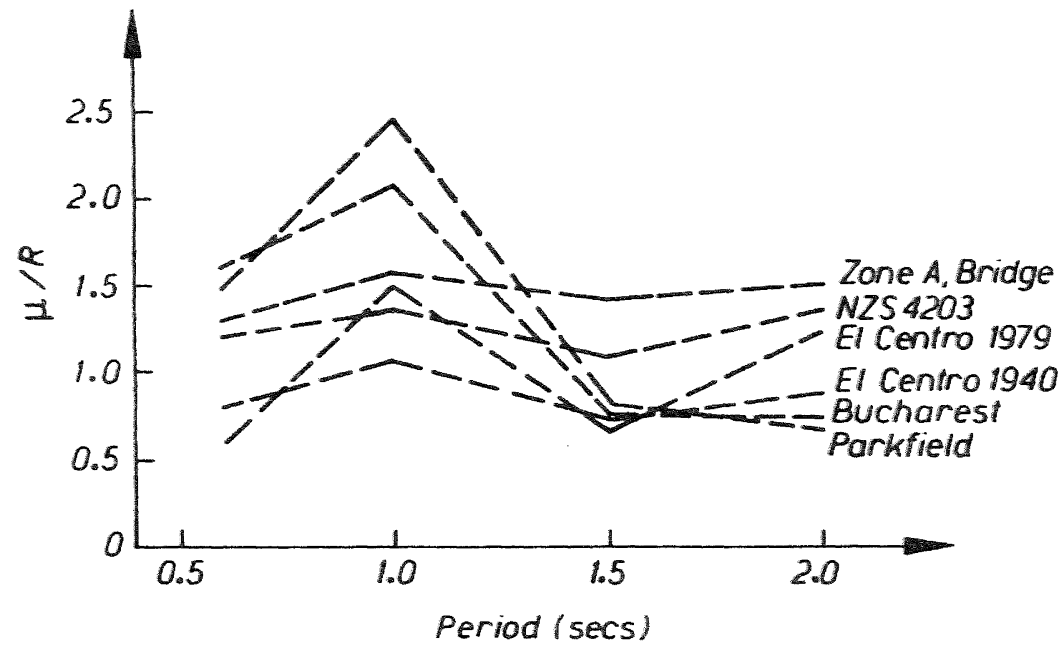

Fig. $13 \mu / R$ Factors for Steel Frames Under Different Earthquakes

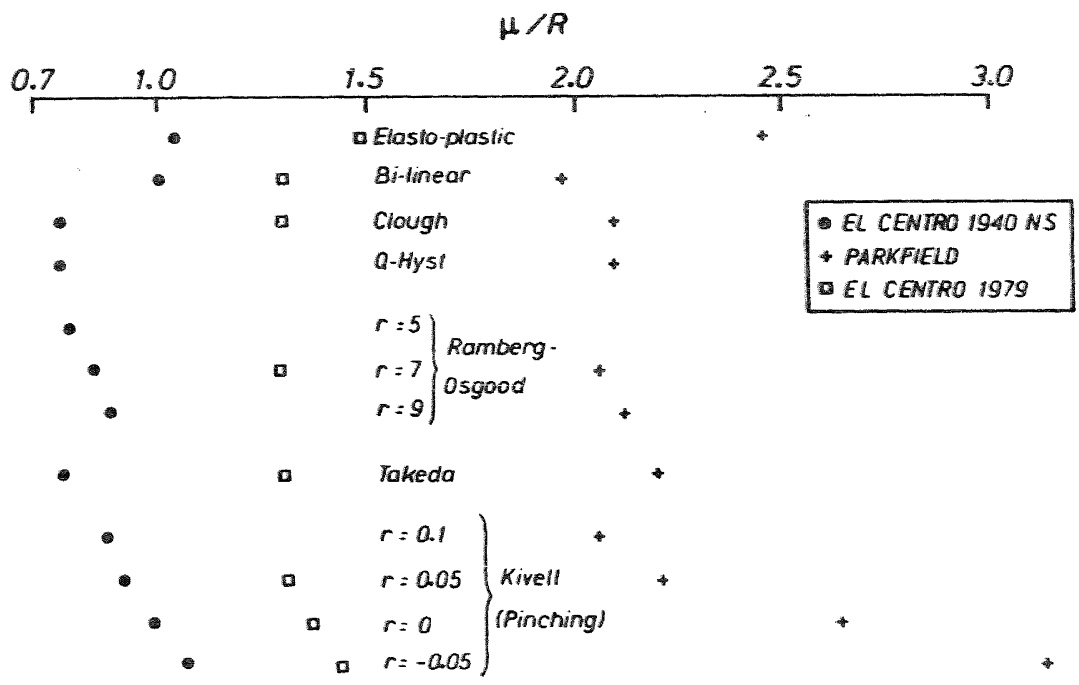

Fig. $14 \mu / R$ Factors for Different Hysteresis Models and Three Different Earthquake Accelerograms of a Frame of 1 Second Period with $\mathrm{R}=4$ 

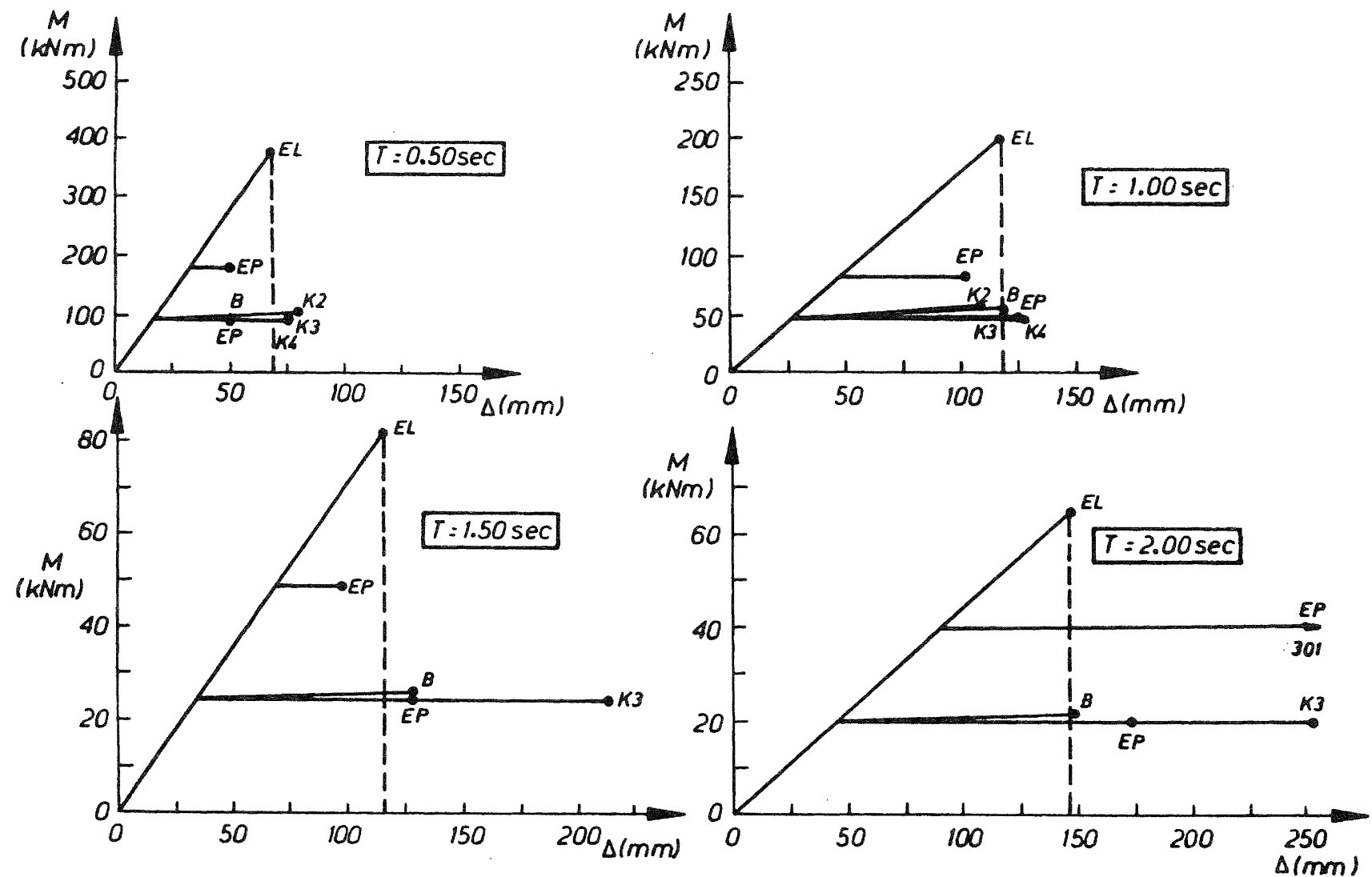

Fig. 15 Comparison of Elastic and Inelastic Responses for Timber Frames of Different Periods Under the El Centro 1940 Earthquake
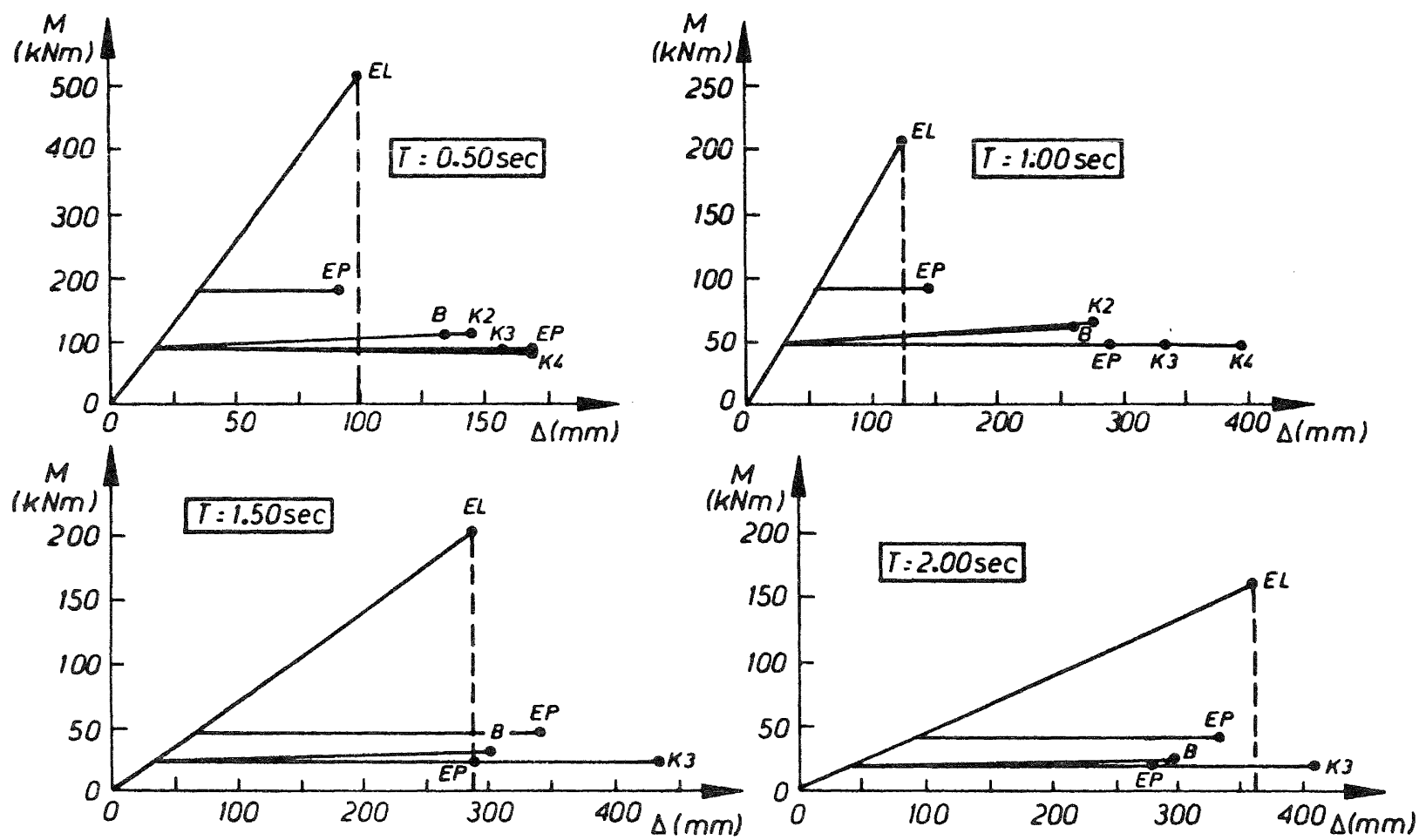

Fig. 16 Comparison of Elastic and Inelastic Responses for Timber Frames of Different Periods Under the Parkfield Earthquake 

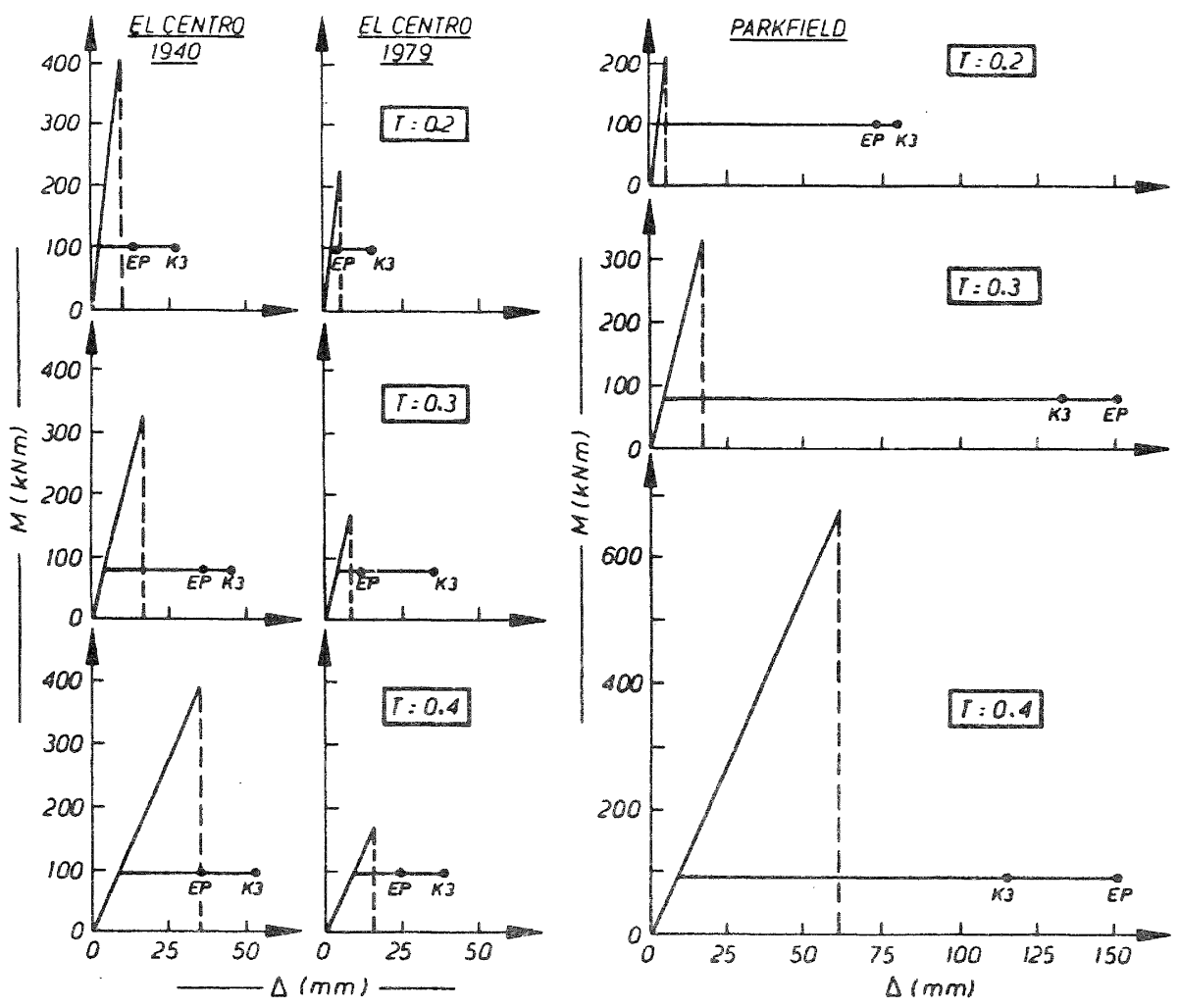

Fig. 17 Comparison of Elastic and Inelastic Responses for Timber Frames where $\mathrm{R}=4$ for $0.2,0.3$ and 0.4 Second Periods Under Different Earthquakes
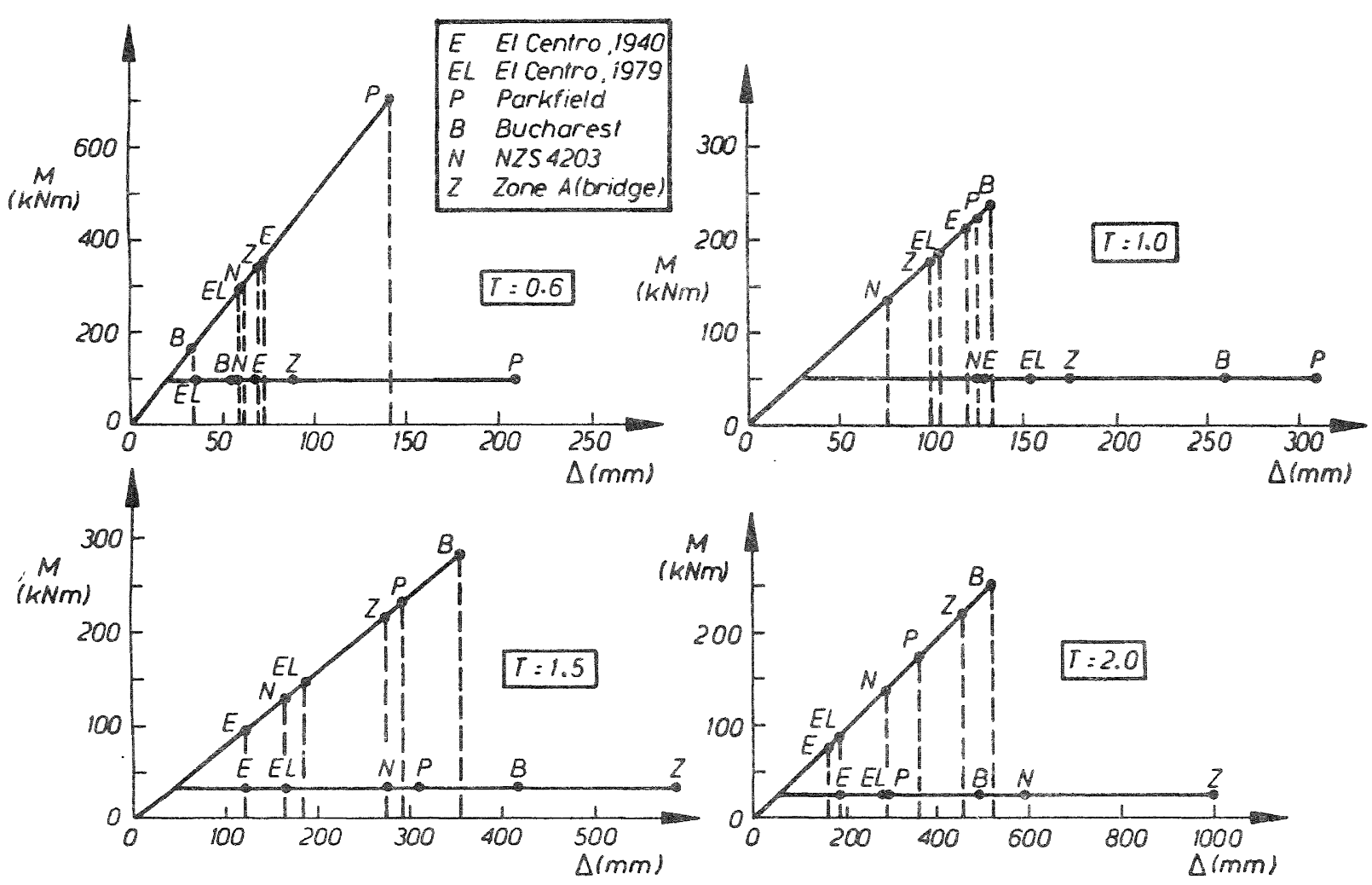

Fig. 18 Comparison of Elastic and Inelastic Response for Elastoplastic Steel Frames $(R=4)$ of Different Periods Under Several Earthquakes 


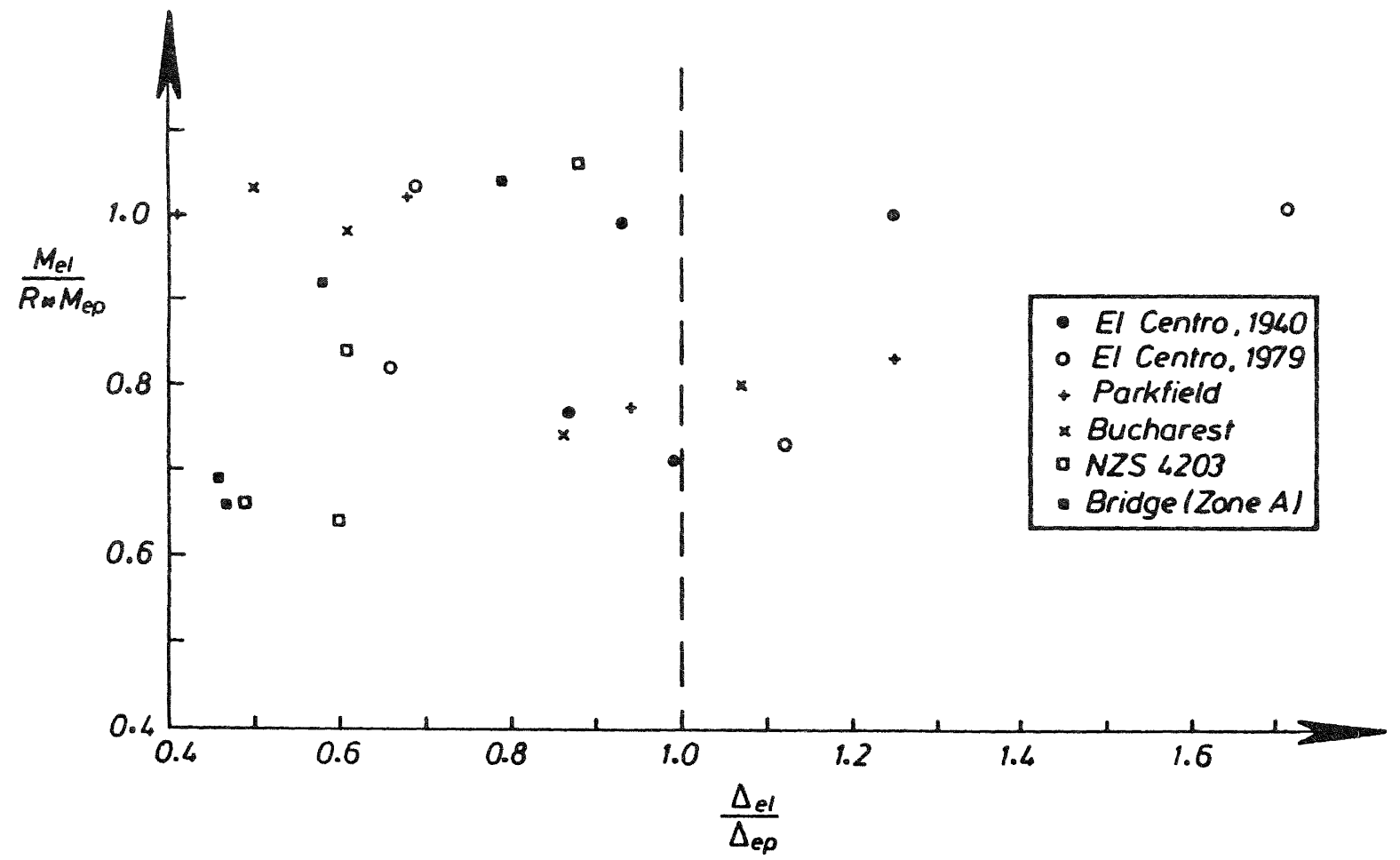

Fig. 19 Comparison of the Nondimensionalised Moment Against the Nondimensional Displacement for Elastoplastic steel Frames
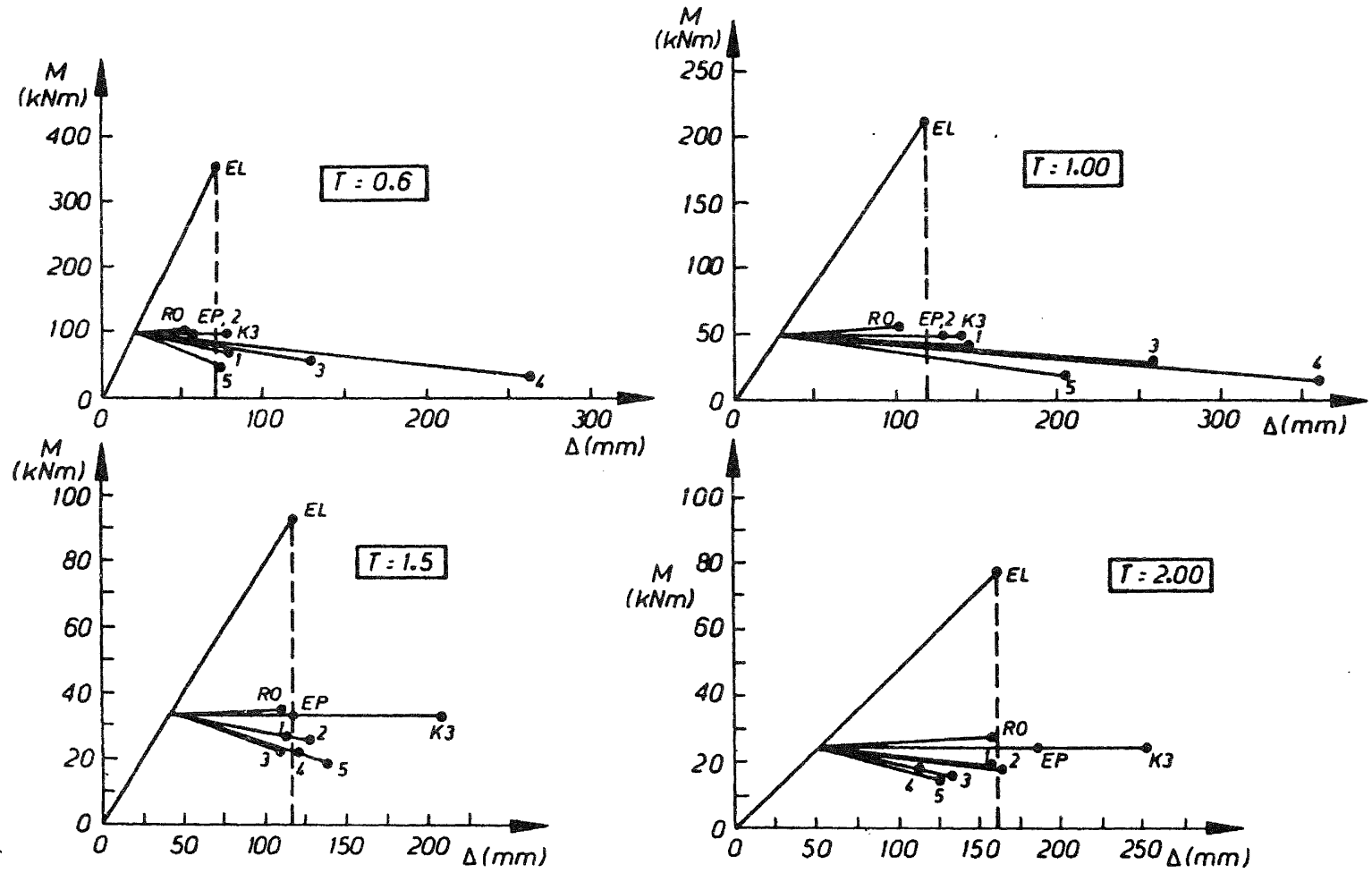

Fig. 20 Comparison of Elastic and Inelastic Response for Steel Frames Under El Centro 1940 Earthquake and Having Different Levels of Strength Degradation 


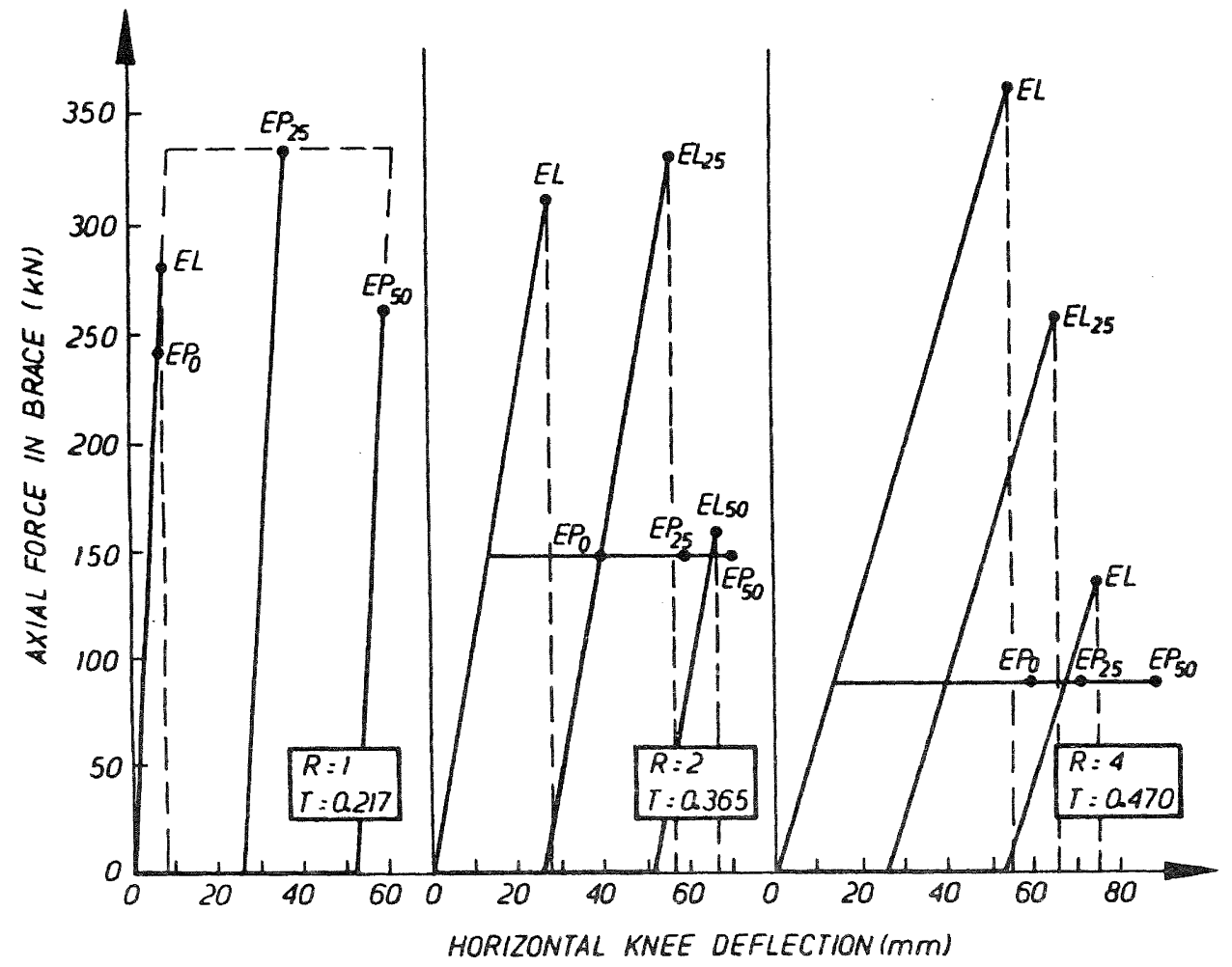

Fig. 21 Axial Force in Brace Against Horizontal knee Deflection for Single Storey Cross-Braced Frame with Three Different Levels of Slackness $(0,25$ and $50 \mathrm{~mm})$ in the Braces, Under the El Centro 1940 Earthquake

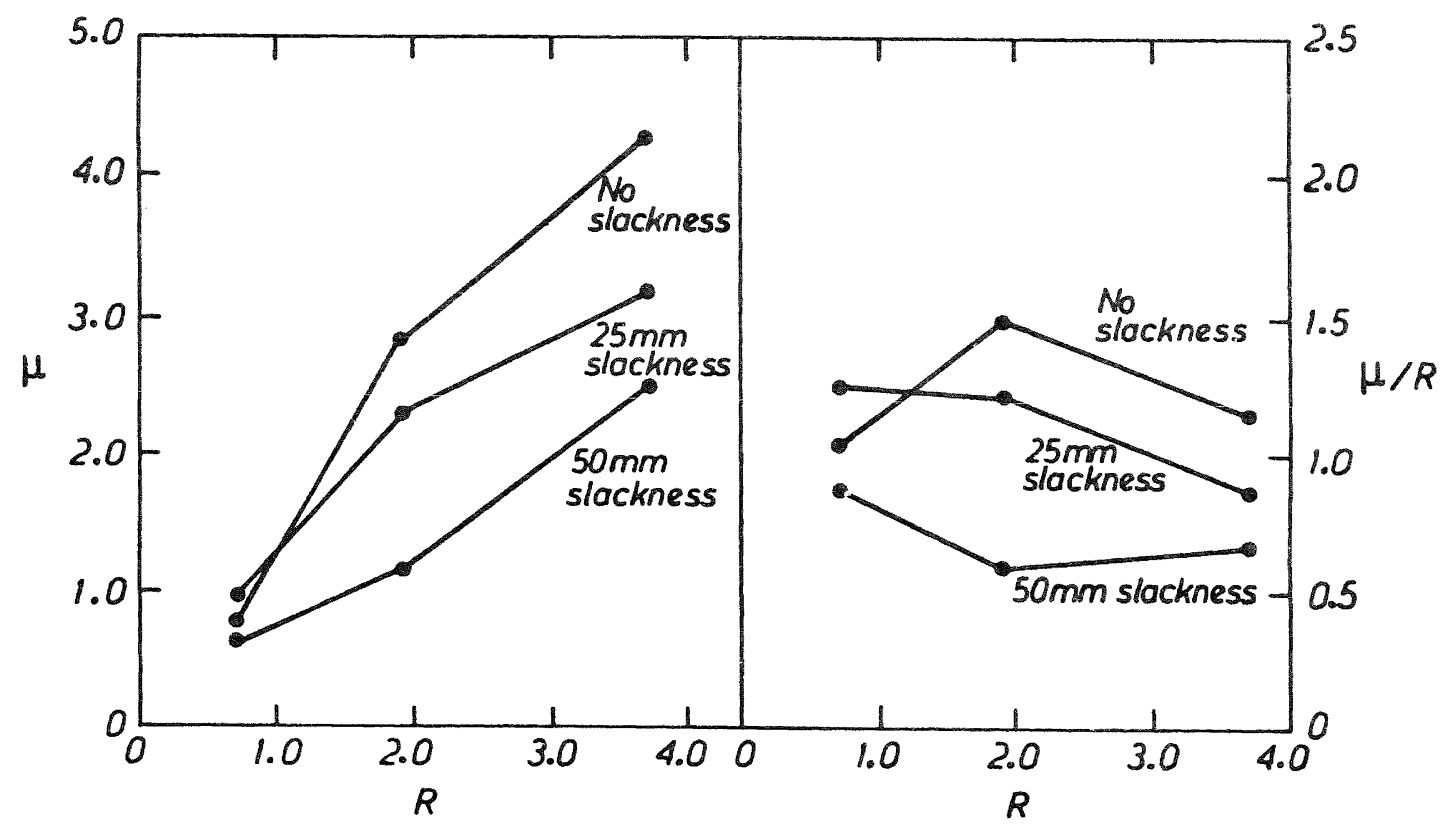

Fig. 22 Required Ductility $\mu$ and the Ratio $\mu / R$ for Single Storey Cross-Braced Frame with Three Different Levels of Slackness in the Braces 
Plots of the required ductility $\mu$ and the factor $\mu / \mathrm{R}$ are shown in figure 22 .

The case where $\mathrm{R}=1$ implies elastic design, nevertheless, one can provide a sufficient cross-sectional area to resist the design force at this level with any larger force producing inelastic behaviour. The results shown in Eigure 21 for $R=1$ seem very erratic with one of the two braces almost yielding when the slackness in the brace was $25 \mathrm{~mm}$ but the maximum brace forces for the cases of no slackness or $50 \mathrm{~mm}$ of slackness do not appear to have reached anywhere near the yield value of $334.8 \mathrm{kN}$.

Also shown in fiqure 21 are the axial force versus deflection relationships allowing for the $25 \mathrm{~mm}$ and $50 \mathrm{~mm}$ slackness.

\section{(d) R-Braced Two Storey steel Frame}

The plot of axial force aginst axial defornation for one leg of the brace is shown in figure 23. The buckling behaviour of either bracing leg was modelled in two ways: (a) as an elasto-plastic yielding member or (b) as a bi-linear elastic merber. The results of figure 23 give some idea of the performance of the $\mathrm{k}$-bracing.

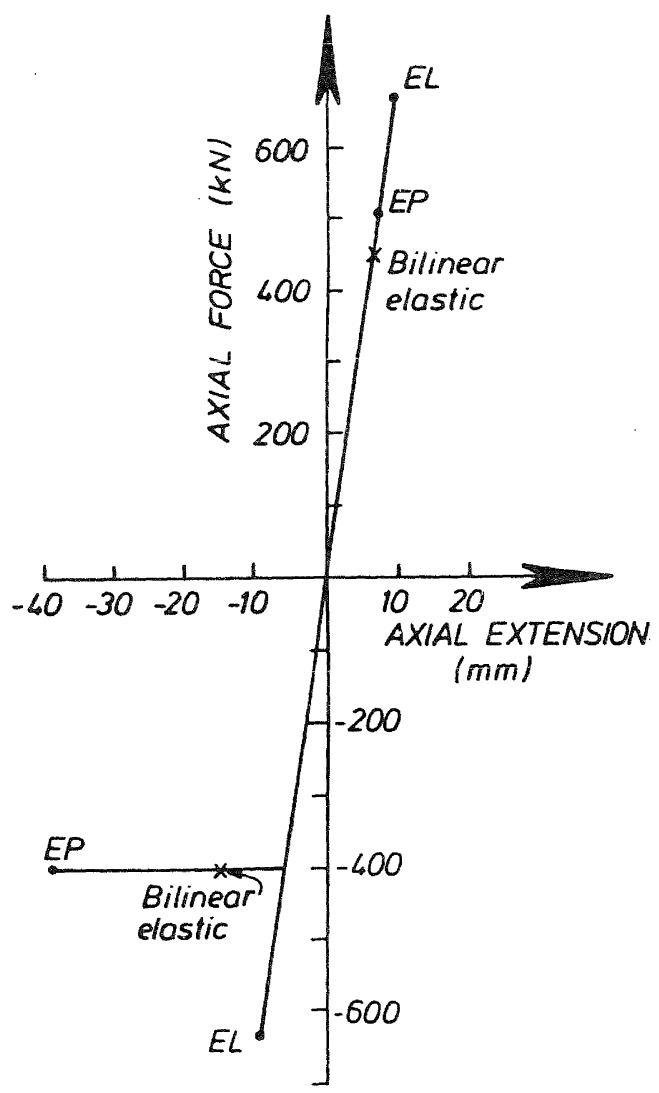

Fig. 23 Axial Force Against Axial Extension on the Braces for a K-Braced Frame Under the El Centro 1940 Earthquake

\section{(e) Eour Storey Timber Erame}

A plot of the maximum first floor moment against the top storey deflection is shown in figure 24 .

The natural period of this frame was 0.94 seconds. It can be seen that the inelastic response of yield moments of 30 or $40 \mathrm{kN} \cdot \mathrm{m}$ are approximately the same as the elastic deflection.

\subsection{DISCUSSION}

It has been felt for quite a long time that the area within the hysteresis loop is important in the reduction of the response of inelastic structures because the area within the loop is a measure of work done in a cycle of inelastic behaviour. This meant that very fat hysteresis loops, such as those exhibited by the bi-linear and Ramberg-osgood rules would be highly desirable and that the detailed design should attempt to replicate this form of loop. Eurther, it has been felt that loops showing pinching or degradation of stiffness are very undesirable as they are likely to lead to larger inelastic displacements.

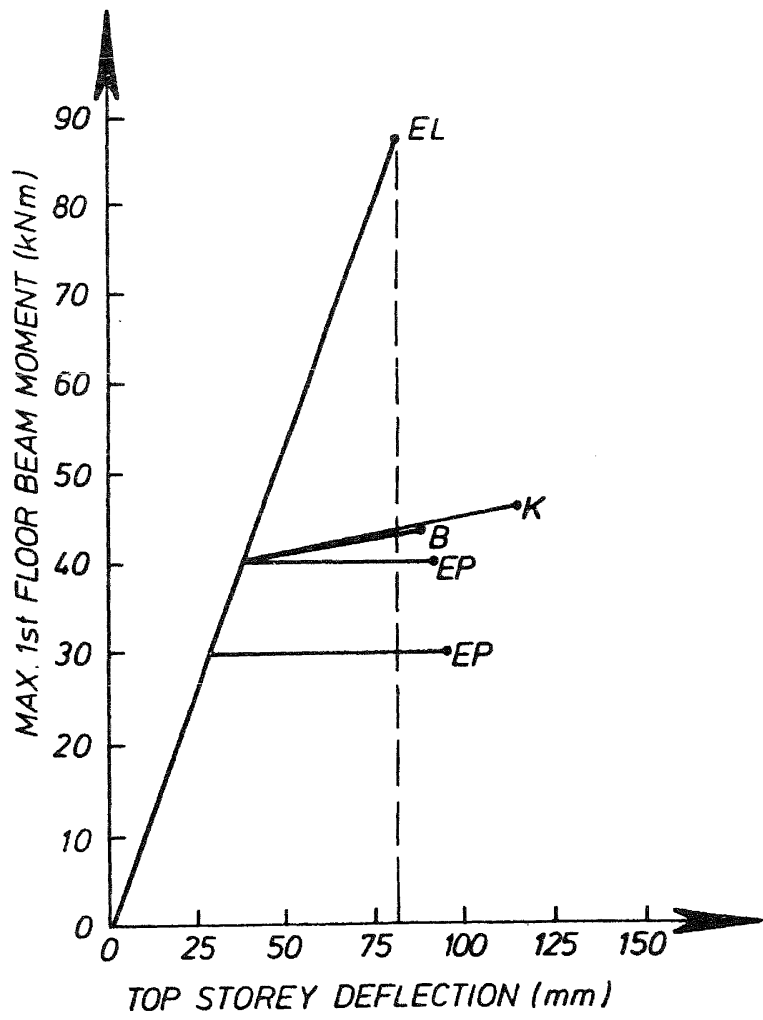

Fig. 24 Maximum First Floor Beam Moment Against Top Storey Deflection for a Four storey, Two Bay Timber Frame, Under the El Centro 1940 Earthquake 
However, during the past decade, Otani [4] and other researchers [5] investigating the response of reinforced concrete structures and more recently Stewart [6] with timber shear-wall structures have shown, that provided the structure possesses some inherent damping or energy dissipating mechanism, the response of the structure is rather insensitive to the shape of the hysteresis 10op.

This study confirms a similar result for the structures that were investigated, see Figures 8, 9, and 10. only the Ramberg-Osgood loop shows any significant drop in the apparent $\mu / R$ values, due probably to the marked post-elastic stiffness exhibited in the range of displacements experienced together with a slight difficulty in defining the meaning of yield displacement.

The largest variation in $\mu / R$ factors appears to be associated with the variation in the exciting accelerogram. This is indicated in the results, see Figures 11 14. Eigures 12 and 13 show the divergent variation of the $\mu / R$ relationships when the portals were subjected to the Parkfield accelerogram. This is particularly marked at periods below 1.5 seconds. Similarly the two artificial records with spectra approximating those of NZS 4203 and the Bridge Design Study Group show greater variations in the longer period range.

The pinching hysteresis shows increased response with some records when it has a negative bi-linear factor. However, in this case, the loop is modelling a structure with degrading strength as well as degrading stiffness and it is felt that a strength degradation within the successive hysteresis loops may be quite significant in the structure's response (see also figure 20 ).

Figures 15 and 16 compare the inelastic responses under the El Centro 1940 and Parkfield earthquakes. It can be seen that in general the bilinear and elastoplastic hysteresis loops give similar results though the pinching (Kivell) model gives greater displacements - except for the 1.0 second period portal under the 1940 El Centro excitation. The values shown for the response of the $R=2$ elastoplastic frames show similar trends to those for the $R=4$ cases .

Comparisons of the behaviour of very short period timber structures $10.2-0.5$ second period) given in figure 17 show that the "equal-displacement" concept holds reasonably well for elastoplastic response under the two El Centro excitations but is quite misleading for the Parkfield excitation. For all three earthquakes the results for the pinching hysteresis loop are much greater than would be predicted by the equal-displacement theory.

In order to further investigate the effect of different earthquakes, the elastic and inelastic responses were compared as shown in figure 18. In general,it shows that for the El centro
1940 excitation the scatter of the results due to variations in the hysteresis loops is small and the "equal-displacement" concept holds reasonably well except above 1.0 second period when there is a much greater increase in response for the pinching hysteresis loops. On the other hand, it shows that for parkfield the "equal-displacement" concept is not valid. While the design seismic force reduction factor, $R$, used was 4 , there appears to be some variation in the actual reduction factor for the El Centro 1940 earthquake. For the El centro earthquake the elastic and inelastic displacements appear to be similar but there is very considerable variation for the other earthquakes. As a further check on this variation, the moment and deflection are shown plotted in a nondimensional form in figure 19. This nondimensionalised moment compares the expected inelastic moment with the inelastic design moment (or it can be taken as the ratio of the elastic moment to the factored yield moment). If the inelastic behaviour of the portals followed the "equal-displacement" concept then the ratio of elastic to inelastic displacement should be unity and the ratio of the elastic moment to the factored yield moment should be close to unity. However, the figure shows very considerable scatter of the results for the different earthquakes with most of the elastoplastic displacements being much greater than the elastic displacements.

It is evident from the results discussed so far that further investigation is required for highly pinched loops and where there is degradation of strength during the cyclic response of the structure. The effect of strength degradation shown in figure 20 is much more pronounced at 1.0 seconds period and below than at higher periods with the variations in the required displacement ductility and the ratio $\mu / R$ being considerable at periods below 1.5 seconds but being small at higher periods.

In the case of the cross-braced frames, figure 21 shows that for the $R=1$ case, the response remains elastic even with slackness in the brace. For the $R=2$ and $\mathrm{R}=4$ frames while increasing slackness in the members increases the deflection at the knee, this increase is not in proportion to the increase in deflection caused by the increase in slackness. The inelastic deflections for the case of a tight brace (i.e. no slackness) under the 1940 El Centro excitation are generally in agreement with the "equal-displacement" concept. Any further work should investigate whether the effect of different earthquake excitations on cross-braced frames is as significant as it has been shown to be for portal frames.

Little can be said about the $\mathrm{K}$-braced frames on the basis of the few analyses carried out - except that more work needs to be undertaken to study the seismic performance of these frames.

The limited results illustrated in figure 24 for the four storey frame suggest 


\begin{tabular}{|c|c|c|c|c|c|c|c|}
\hline \multirow{4}{*}{ persos } & \multirow{4}{*}{$\begin{array}{l}\text { Reguired } \\
\text { M }_{y}\end{array}$} & \multicolumn{6}{|c|}{ Caycuarabed strength (KN.m) } \\
\hline & & \multicolumn{3}{|c|}{ code } & \multicolumn{3}{|c|}{ Sased on 0.4 mas sip } \\
\hline & & \multicolumn{6}{|c|}{ Nan spackng (mon) } \\
\hline & & 20 & 30 & 40 & 20 & 30 & 40 \\
\hline 0.5 & 88.7 & 99.3 & 58.20 & 38.08 & 387.9 & 213.0 & 76.63 \\
\hline 3.0 & 47.9 & 33.80 & 20.95 & 32.42 & 69.98 & 40.16 & 26.28 \\
\hline 3.5 & 29.0 & 33.97 & 6.47 & 3.20 & 27.77 & 32.35 & 9.59 \\
\hline 2.0 & 39.8 & 6.21 & 2.33 & 0.78 & 23.33 & 6.95 & 4.5 \\
\hline
\end{tabular}

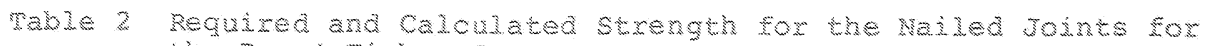
the $R=4$ maber sxames

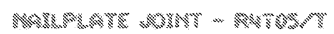

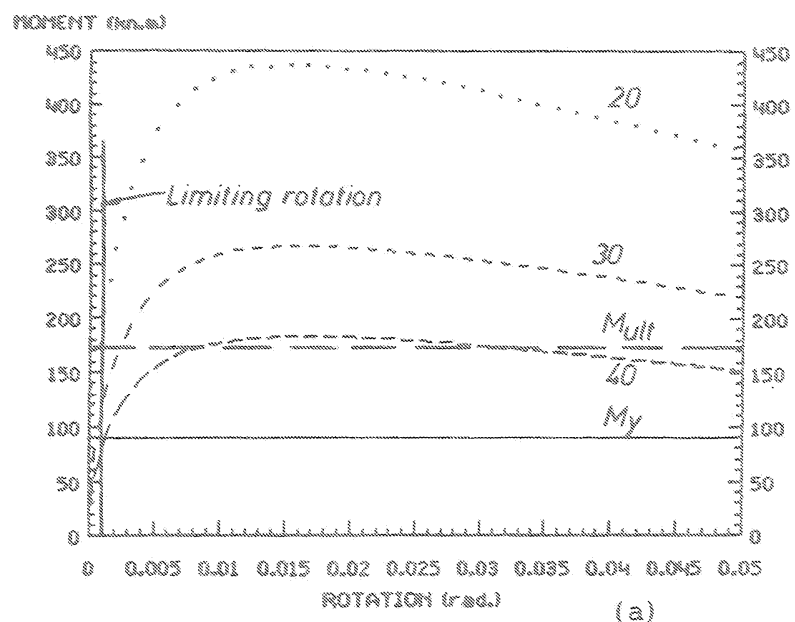

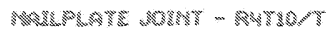

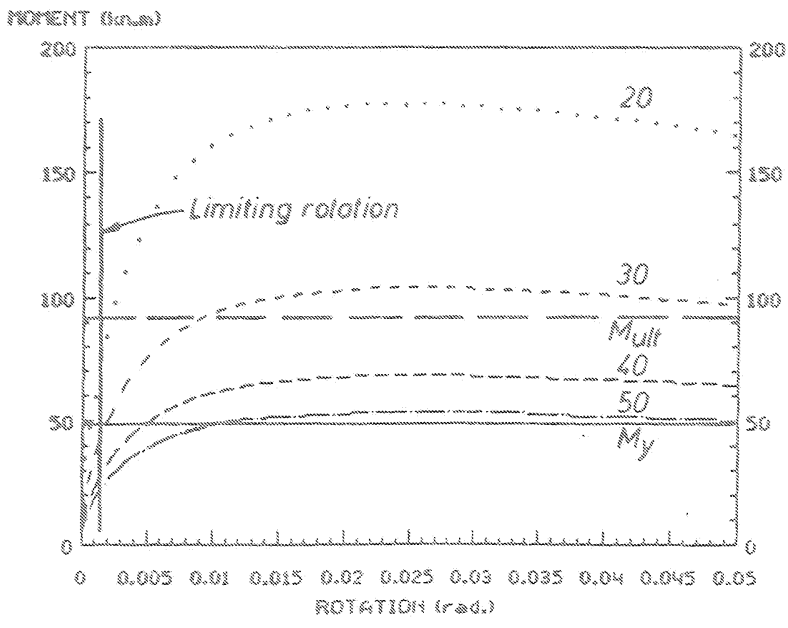

(c)
Mara

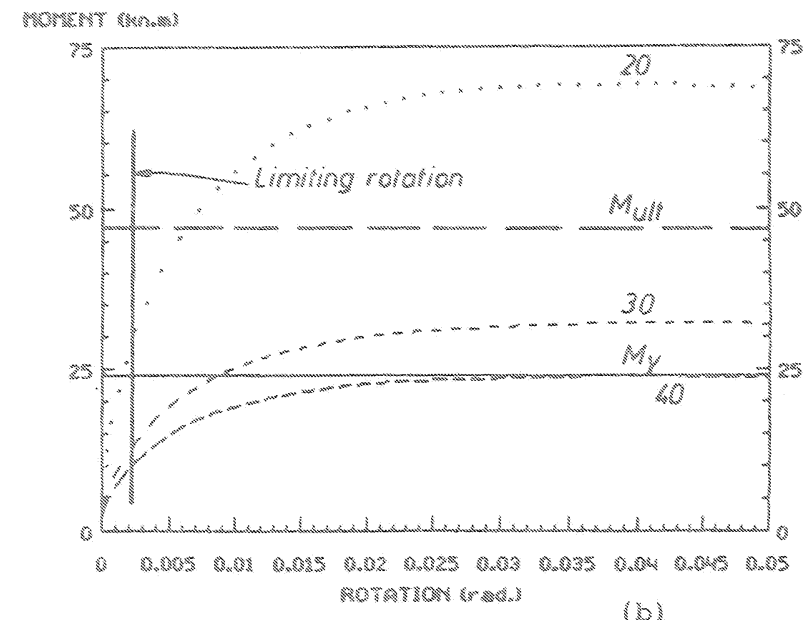

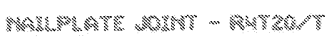

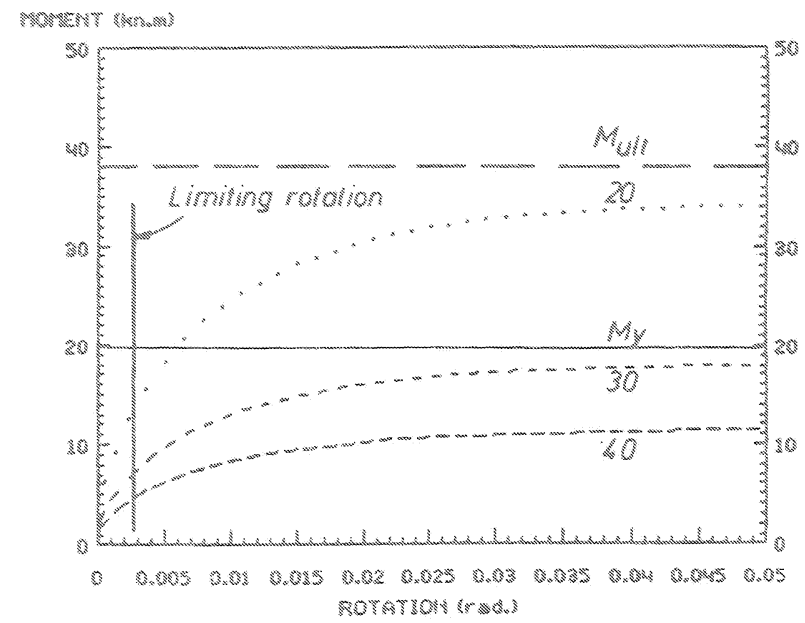

$(d)$

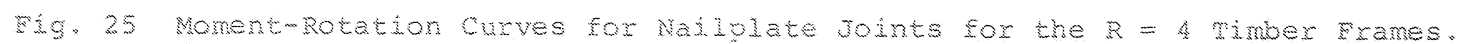

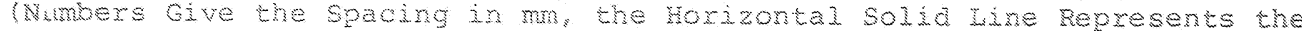
Design Joint yiele Moment and the Horizontal Dashed Line Represents the Uimate Timber strength) (a) 0.5 second period

(b) 1.0

(c) 2.5

(a) 2.0

":

ss 
that the "equal-displacement" concept may be valid for this particular frame, under the 1940 El Centro excitation.

\subsection{Timber Portal Fraines}

As outlined in the Introduction, care needs to be taken in matching the strength of the joint with that of the members. Table 2 shows details relating to the joints needed for the $R=4$ designed frames, covering the required yield moment and the calculated strength for a rectangular pattern of nailing through steel side plates. The strength has been calculated for nail spacings of 20,20 and $40 \mathrm{~mm}$ using $4 \mathrm{~mm}$ diameter nails using the NZS 3603 [8] nail loads as well as using an "average" load-slip curve [11] to determine the actual load carried by the nails when the outer nails had undergone a slip of 0.4 mn. The latter values can be seen to be about twice the code values suggesting an implied factor of safety of about two for the code values.

Moment-rotation curves for the possible nailplate joints for the $R=4$ timber portals are shown in figure 25 , with the numbers on the curves being the nail spacing in $\mathrm{mm}$. The solid horizontal lines represent the required yield moments for the joints. The curves in figure 25 should be compared with the values given in Table 2. The various curves were obtained by using an "average" load-slip curve for the nailed joints [11] to determine the load carried by all the nails in the nail group with the moment resisted being given by summing the torsional moment contribution of each nail. The curves thus show the ultimate strength of each joint. The maximum values of moment sustained by each joint can be seen to be considerably greater than the design values given in Table 2.

Also shown in figure 25 are the dashed horizontal lines representing the ultimate bending strength of the column members.

In order to obtain a ductile failure in the joint rather than a brittle failure in the members, care must be taken to ensure that the ultimate strength of the members is greater than that of the joint. For instance, in the case of the 0.5 second period frame, the code strength design values might suggest that a $20 \mathrm{~mm}$ nail spacing was necessary to ensure adequate strength whereas Eigure 25 shows that at this spacing the joint strength would be more than twice that of the timber member. hence leading to a brittle failure instead of the required ductile one.

A serious consequence of reducing nail spacing to achieve the desired low ultimate strength is that the joint has very low rotational stiffness. This low stiffness will result in a much longer period than that assumed on the original analysis.

This conflict between stiffness and strength means that there is difficulty achieving significant ductility.
Consequently, this subject requires significant further study before practical ductile frames in timber can be achieved.

\subsection{CONCLUSIONS}

The conclusions from the results obtained are:

1. As observed by several other researchers the variation in the hysteresis loop shape is not a major influence in the dynamic response of inelastic structures subjected to earthquake excitation. This is not unexpected in structures that possess some inherent damping, for although a small initial increment of damping has a marked effect on the response spectra of an undamped structure further increments of damping have a rapidly diminishing effect as the amount of damping present in the structure increases.

2. The "equal-displacement" concept is not valid over the range of periods for which the present codes assume it to be. The concept holds approximately for the El Centro 1940 excitation, but is far from the mark for certain other major earthquakes. This means that the ductility demand implied by NZS $4203(\mu=4 / S M)$ may be greatly exceeded if certain types of earthquakes occur.

3. Part of this project investigated the validity of the basic assumptions described above. Once ductility demands associated with various design levels, have been determined. it will be necessary to look more closely at details and design procedures to establish whether the ductility demands can be reasonably met. It will be necessary in due course to establish a capacity design procedure to ensure that the desirable behaviour is enforced without brittle fracture of timber members leading to sudden collapse.

4. For timber portal frame structures it is very difficult to achieve a high enough stiffness together with a low enough strength to ensure satisfactory ductile behaviour in the joint.

\subsection{ACKNOWLEDGMENTS}

The research reported above is study undertaken on behalf of BRANz. The authors are grateful to BRANZ for their support of this research. 


\subsection{REFERENCES}

1. Kivell, B.T., Moss, P.J.and Carr, A.J., "Hysteretic Modelling of Moment-Resisting Nailed Timber Joints", Bull. N.2. Earthq. Eng. Soc., Vol. 14, No. 4, 1981, pp.233243.

2. Sharpe, R.D., "Ground Motions for New Zealand Seismic Design" Bridge Design and Research Seminar, National Roads Board, Auckland, 1984, pp.49-54

3. Priestley, M.J.N. and Park, R., "strength and Ductility of Bridge Substructures, Chapt. 2", RRU Bulletin 71, 1984, p.7.

4. Otani, S., "Nonlinear Behaviour of Reinforced concrete Building Structures Especially Under Earthquake Motions", IASS Symposium on Nonlinear Behaviour of Reinforced Concrete Spatial structures. Darmstadt, July 1978.

5. Umemura, $H$. and Takizawa, $H$. "Dynamic Response of Reinforced concrete Buildings", Structural Engineering Documents 2, IABSE, Zurich, 1982.

6. Stewart, W.G., Dean, J.A. and Carr, A.J., "The Seismic Performance of Plywood Sheathed Shearwalls" Proc. Pacific Timber Engineering Conference, Auckland, May 1984 . $\mathrm{pp} .486-495$.

7. Standards Association of New Zealand, "Code of Practice for General Structural Design and Design Loadings for Buildings", NZS 4203:19181, SANZ, New Zealand, 1981.

8. Standards Association of New Zealand, "Code of Practice for Timber Design", NZS 3603:1981, SANZ, New Zealand, 1981 .

9. Moss, P.J., "Seismic Performance of a Multi-storied Timber Frame having Moment-Resisting Nailed Joints" Proc. Pacific Timber Engineering Conference, Auckland, May 1984, pp. $559-568$.

10. Dean, J., Stewart, W.G. and Carr, A.J." "The Seismic Behaviour of Plywood Sheathed Shearwalls" Bull. N.Z. Earthg. Eng. Soc.. Vol. 19, No. 1, 1986, pp 48-63.

11. Thurston, S.J. and Flack, P.F. 'Cyclic Loading of Large Timber $R$ Joints Incorporating Nailed Steel Side Plates", N.Z. Ministry of Works and Development, Central Laboratories, Report No. 5-79/6. 1979. 